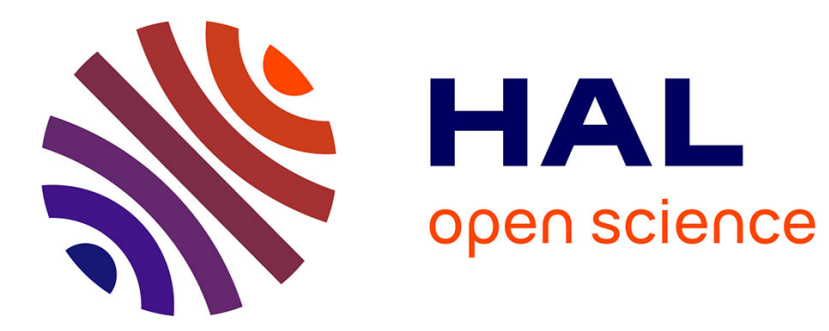

\title{
Pareto-improving structural reforms
}

Gilles Saint-Paul

\section{To cite this version:}

Gilles Saint-Paul. Pareto-improving structural reforms. 2018. halshs-01972036

\section{HAL Id: halshs-01972036 \\ https://shs.hal.science/halshs-01972036}

Preprint submitted on 7 Jan 2019

HAL is a multi-disciplinary open access archive for the deposit and dissemination of scientific research documents, whether they are published or not. The documents may come from teaching and research institutions in France or abroad, or from public or private research centers.
L'archive ouverte pluridisciplinaire HAL, est destinée au dépôt et à la diffusion de documents scientifiques de niveau recherche, publiés ou non, émanant des établissements d'enseignement et de recherche français ou étrangers, des laboratoires publics ou privés. 


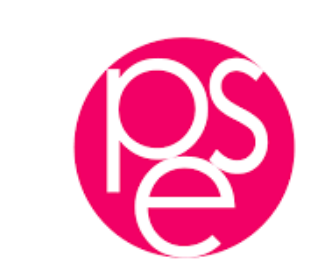

PARISSCHOOL OFECONOMICS
ECOLED'ECONOMIEDE PARIS

WORKING PAPER N $2018-56$

Pareto-improving structural reforms

Gilles Saint Paul

JEL Codes: E64, H21, P11

Keywords: Structural reform, deregulation, price controls, Pareto optimality, rent seeking, taxation, compensatory transfers
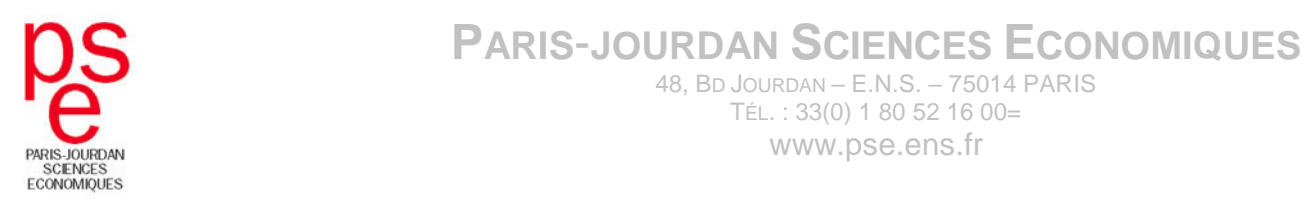


\title{
Pareto-improving structural reforms
}

\author{
Gilles Saint-Paul ${ }^{1}$ \\ Paris School of Economics (ENS-PSL) \\ NYU Abu Dhabi
}

December 5, 2018

\footnotetext{
${ }^{1}$ This research has benefitted from financial support from CEPREMAP and the PGSE Ecole Universitaire de Recherche. I am grateful to Florin Bilbiie and seminar participants in Padova for helpful comments and suggestions.
} 


\begin{abstract}
Economists recommend to partly redistribute gains to losers from a structural reform, which in many cases may be required for making the reform politically viable. However, taxation is distortionary. Then, it is unclear that compensatory transfers can support a Pareto-improving reform. This paper provides sufficient conditions for this to occur, despite tax distortions. I consider an economy where workers have sector-specific skills and some sectors are regulated by a price floor. Transfers have to be financed by proportional taxation on firm's revenues or, equivalently, labor income. Labor supply is elastic to net post-tax real wages, and hence reduced by taxation. In a setting where preferences are isoelastic, deregulation is implementable in a Paretoimproving way through compensatory lump-sum transfers, despite that these are financed by distortionary taxes. In a more general setting, there always exist Pareto-improving reforms but they may involved tightening regulation for some goods. I provide sufficient conditions for deregulation, i.e. a general reduction in price floors, to be Pareto-improving. They imply that demand cross-price elasticities should not be too large and that the reform should not be too unbalanced. Finally, I consider counter-examples where some people earn rents associated with informational or institutional frictions. In such situations, Pareto improvements are unlikely. If losers have veto power, the reform may only be supported by a minority of people. Broadening reform scope is especially useful to raise its political support when its impact is uneven across consumers.
\end{abstract}

Keywords: Structural reform, deregulation, price controls, Pareto optimality, rent seeking, taxation, compensatory transfers

JEL:E64, H21, P11. 


\section{Introduction}

Structural reforms in labor and product markets are commonly advocated by economists. Regulations that distort prices, unless they are tailored to correcting an externality, lead to an inefficient allocation of resources. Common economic sense suggests they should be removed. However, the efficiency gains that are generally associated with such reforms are aggregate ${ }^{1}$. For example, removing a price floor on agricultural products allows additional units whose marginal cost is lower than the consumers' marginal willingness to pay to be produced; nevertheless, agricultural producers lose from such a reform, while more than $100 \%$ of the aggregate gains accrue to consumers. Economists generally recommend to redistribute the gains to losers from the reform, which in many cases may be required for making the reform politically viable ${ }^{2}$. If such redistribution can be financed through lump-sum taxes, aggregate gains can be reallocated so as to implement the reform in a Pareto-improving fashion. However, taxation is generally distortionary. If such distortions are taken into account, it is unclear that a set of compensatory transfers can be designed so as to make the reform Pareto-improving. In such a situation, claims that the reform promotes economic efficiency are irrelevant; de facto, the reform benefits some groups at the expense of others, and it is legitimate for the losers to consider such claims as an ideology in favor of the winning social groups.

At face value, the view that tax distortions are likely to prevent Paretoimproving structural reforms makes a lot of sense: The aggregate gains from reform are generally small relative to their distributive effects (the former are

\footnotetext{
${ }^{1}$ It is not the place here to discuss the huge literature attempting to evaluate the aggregate effects of structural reforms. For a recent survey, see for example Campos et al. (2017).

${ }^{2}$ For example, Delpla and Wyplosz (2007) propose to implement rents buyback schemes for a number of French regulations, including in particular barriers to entry in industries such as taxis and retail trade. A formal result regarding gains from trade can be found in Grandmont and MacFadden (1972).

See Castanheira et al. (2006) for case studies of structural reforms in Europe with an emphasis on the role of coalition building when implementing structural reforms.
} 
a "triangle", the latter a "rectangle") ${ }^{3}$. In turn, this makes the welfare losses from distortionary taxation of the same order of magnitude as the aggregate welfare gains.

For example, in partial equilibrium, consider a good whose price is pegged above the equilibrium market price. Let $p(x)$ be the inverse demand function, and $c(x)$ be the marginal cost function. Consider a reform which reduces the regulated price. by an amount $d p$, thus increasing the quantity transacted by $d x>0$. The change in consumer surplus is $d C S=-p^{\prime}(x) x d x>0$. The change in producer surplus is $d P S=\left(p(x)-c(x)+p^{\prime}(x) x\right) d x$, and it is negative if the markup obtained through regulation is lower than the monopoly one. Let $\lambda$ be the welfare cost of public funds. To implement the reform in a Pareto-improving way, I need to transfer an amount equal to $-d P S$ to the producers and to compensate the rest of society for the welfare loss of the additional taxes. Hence total additional taxes $d T$ must be such that $d T=\lambda d T-d P S$, i.e. $d T=-\frac{d P S}{1-\lambda}$. The total effect on social welfare of the reform and the associated fiscal scheme is therefore equal to $d C S+d P S-\lambda d T=\frac{p-c+\lambda x p^{\prime}}{1-\lambda}$. For this to work we need that

$$
\lambda \leq-\frac{p-c}{x p^{\prime}}=\eta_{D} \frac{\mu-1}{\mu}
$$

where $\eta_{D}=\frac{p}{x p^{\prime}}$ is the elasticity of demand and $\mu=p / c$ is the markup. At face value, (1) has no particular reason to hold. However, if tax rates are set optimally and there is no resource cost of collecting taxes, $\lambda$ is smaller than the distortions induced by any given method of tax collection. Consider then the distortions associated with an excise tax on the good we consider. A small $\operatorname{tax} d \tau$ generates revenues equal to $x d \tau$ and reduces output by $d x=d \tau / p^{\prime}$. The (negative) welfare gain is $(p-c) d \tau / p^{\prime}$, i.e. $\frac{p-c}{x p^{\prime}}$ per unit of tax collected, which coincides with the RHS of (1). Hence (1) always holds.

\footnotetext{
${ }^{3}$ This observation lies at the root of the theory of rent-seeking (Tullock $(1967,2003)$, Krueger (1974)). In a rent seeking society, the rents to beneficiaries of distortions have been dissipated ex-ante in the resources these groups have spent to conquer the rents. This somewhat reinforces the legitimacy of compensating losers, who would otherwise be strictly worse-off than the winners from a lifecycle perspective.
} 
This just means that as long as taxation can mimic the effect of regulation, we can always replace the latter by some tax scheme; the optimal tax scheme Pareto-dominates this. In particular, this argument casts doubt upon the view that reform may be blocked due to budgetary issues such as excess debt or restrictions on deficits imposed by fiscal rules (see Beetsma and Debrun (2004)). The welfare costs of an additional burden on the budget has to be balanced against the welfare costs of the distortion being removed, which should in principle be higher ${ }^{4}$.

The positive results that I provide below elaborate on this theme, in a general equilibrium context.

The idea of implementing a Pareto-improvement through a tax which, although distortionary, leaves the vector of consumer prices unchanged has been proposed in the context of the analysis of trade restrictions by Dixit and Norman (1980a,b). The present paper can be viewed as an application of their ideas to the context of price regulations with entry barriers. Another important related paper is Grüner (2002), who, focusing on labor market reform, shows that, even if lump-sum transfers are possible, compensatory tax schemes may fail to implement a Pareto-improvement if worker type is unobservable because of informational rents ${ }^{5}$. While my focus here is essentially on the distortionary effects of taxes on labor supply, rents play a role in the counter-examples of Section 5, where I discuss the effect of reform scope on reform support.

\footnotetext{
${ }^{4}$ The result could be overturned, though, if there are administrative costs of taxation, in addition to their distortionary effects on supply and demand.

${ }^{5}$ In contrast, Saint-Paul (1994) finds that a redistributive system based on distortionary transfers and taxes generally dominates minimum wages, although this is not in general but for a wide range of parameter values. The differences between that paper and Grüner's are many. In particular, unlike Grüner, in that paper I do not have an unobservable disutility of labor, so there are no informational rents being reaped by a subset of the unskilled workers who potentially lose from a removal of the minimum wage.

Reform may also be blocked due to dynamic contractual failures that are associated with lack of commitment, as in for example Alesina and Drazen (1991), Fernandez and Rodrik (1991), Saint-Paul (1993), Dewatripont and Roland (1992), Saint-Paul et al. (2016). While any distortion, including the unavailability of lump-sum taxes, arguably comes from contractual failures, the issues discussed in the present paper are obviously very different from these paper's approaches.
} 
I first study a simple, symmetric model where each good is produced with a specific type of labor and a subset of goods are regulated by a price floor, implying that some rationing of labor supply must be forced upon the suppliers of those goods. I consider two types of deregulations: an extensive reform which entirely deregulates a subset of the regulated goods, and an intensive one which reduces regulated prices uniformly across the regulated goods. I show that each reform can be implemented in a Pareto-improving way through a combination of a distortionary proportional tax on labor and a lump-sum transfer paid to each worker in the deregulated sectors. The following section generalizes those results by doing away with the symmetry and functional forms assumptions. I show that a Pareto improvement exists provided one can tax each sector's specific labor at its own proportional rate and at the same time pay to it a fixed nonnegative lump-sum transfer. But such a reform need not involve deregulation, i.e. some regulated prices may have to go up. I provide sufficient conditions on preferences and the design of reform for deregulation (i.e. a reduction in all regulated prices) to be implementable in a Pareto-improving way through proportional taxes and lump-sum transfers. Finally, I discuss some counter-examples, which, as in Grüner (2002), rest on some groups being able to reap rents from the compensatory tax schemes ${ }^{6}$. In one example, taxes cannot be differentiated across groups and the indexation rule for setting regulated prices is such that workers who remain regulated gain less, in consumption terms, that nonregulated citizens. As a result, the tax rate that makes them indifferent between reform and the status quo is lower. In the absence of tax differentia-

\footnotetext{
${ }^{6}$ See also Guesnerie and Roberts (1987), Marceau and Broadway (1994). Grüner shows that in the context of labor market reforms, the number of losers from reform who are able to reap informational rents may be so large that no reform may get support from a majority. Here this is not the case: I consider product market reforms such that (in general) only a minority of workers may face deregulation. However my results imply that if for some reason the losers from reform have veto power, then majority support may fail again.

Empirically, Buti et al. (2008), find no significant effect of structural reform on reelection probabilities, which may be due to reforms with too many losers not happening in the first place.
} 
tion across groups, therefore, rents accrue to nonregulated consumers, which reduces the total tax receipts available to compensate the deregulated groups for their losses from the reform. I show that this makes Pareto-improving reform far less likely. In another example, people differ in which goods they consume. Some consumers gain more than others because deregulated goods account for a bigger share of their consumption basket. Again, one cannot differentiate the tax rate across people and a Pareto-improvement is unlikely. Also, if the deregulated groups have veto power, implying that no accompanying fiscal scheme can leave them worse-off than in the status quo, it is easy to produce examples where no reform can get a majority support. My simulations also show that, at least over some range, widening the scope for reform (i.e. raising the number of goods that are deregulated) is likely to raise its total support, thus confirming the importance of reform scope and complementarities, which was pointed out in other contexts by Blanchard and Giavazzi (2003), Caselli and Gennaioli (2008) or Ilzetski (2018) ${ }^{7}$ : losers from reform in one area are partially compensated (as consumers) by their gains from reform in another area.

\section{The model}

There is a continuum of consumers-producers over $[0,1]$, indexed by $i$. Consumers with index $i$ are endowed with a specific labor input which only allows them to produce good $i$.

All consumers have the same utility function, given by

$$
U\left(\left\{c_{i j}\right\}, l_{i}\right)=\left[\int_{0}^{1} c_{i j}^{\alpha} d j\right]^{1 / \alpha}-\frac{l_{i}^{\gamma}}{\gamma},
$$

where $c_{i j}$ denotes consumption of good $j$ by consumer $i$ and $l_{i}$ his labor supply. I assume $-\infty<\alpha<1$ and $\gamma>1$.

\footnotetext{
${ }^{7}$ See also Coe and Snower (1997), who focus on complementarities across various dimensions of labor market reforms in their effect on employment, as well as Grüner (2013). For a less positive view about complementarities, see Amable et al. (2007).
} 
Each good $j$ is produced with a linear technology, using its corresponding specific labor as the only input:

$$
y_{j}=l_{j}
$$

I assume that a fraction $r$ of the goods are regulated. Goods such that $i>r$ are unregulated. By symmetry, they all have the same equilibrium price, normalized to $p_{N}=1$. Goods such that $i<r$ are regulated: their price cannot fall below some $p_{R}>1$, where $p_{R}$ is fixed by law. Accordingly, barriers to activity ensure that supply is rationed: people such that $i<r$ cannot supply more than a maximum amount of labor $\bar{l}$ to the market. Again, by symmetry, $\bar{l}$ is the same for all goods such that $i<r$.

Clearly, the wage for labor $i$ coincides with the price of the corresponding good.

For a consumer with income $R$ and labor supply $l$, the indirect utility function is

$$
V(R, l, p)=\frac{R}{p}-\frac{l^{\gamma}}{\gamma}
$$

where $p$ is the aggregate price index

$$
p=\left(r p_{R}^{-\frac{\alpha}{1-\alpha}}+1-r\right)^{-\frac{1-\alpha}{\alpha}} .
$$

The corresponding demand for a good of type $k \in\{R, N\}$ is

$$
c\left(R, p, p_{k}\right)=R p^{\frac{\alpha}{1-\alpha}} p_{k}^{-\frac{1}{1-\alpha}} \text {. }
$$

From there it is straightforward to compute the equilibrium. Non regulated households set their labor supply so as to maximize $V(l, l, p)$, yielding

$$
l=l_{N}=p^{-\frac{1}{\gamma-1}} .
$$

Consequently, they consume

$$
c_{N k}=p^{\frac{\alpha}{1-\alpha}-\frac{1}{\gamma-1}} p_{k}^{-\frac{1}{1-\alpha}}
$$

of each good of type $k$. Their resulting utility is

$$
u_{N}=\left(1-\frac{1}{\gamma}\right) p^{-\frac{\gamma}{\gamma-1}}
$$


As for regulated households, their income is $p_{R} \bar{l}$, so that they consume

$$
c_{R N}=p^{\frac{\alpha}{1-\alpha}} p_{R} \bar{l}
$$

of non regulated goods and

$$
c_{R R}=p^{\frac{\alpha}{1-\alpha}} p_{R}^{-\frac{\alpha}{1-\alpha}} \bar{l}
$$

of regulated ones.

To compute the equilibrium $\bar{l}$, we just write down that supply equals demand for any nonregulated good. By Walras's law, regulated markets will then also be in "equilibrium", in that demand will equal the regulated level of supply $\bar{l}$. If the government fails to set $\bar{l}$ equal to this level, the rationing scheme will be inconsistent. Thus $\bar{l}$ is such that

$$
l_{N}=r c_{R N}+(1-r) c_{N N} .
$$

Indeed the LHS is the supply of a nonregulated good, while the RHS sums up the demand for that good across consumer types. Substituting (5), (4) and making use of (2), we get that

$$
\bar{l}=p^{-\frac{1}{\gamma-1}} p_{R}^{-\frac{1}{1-\alpha}},
$$

which allows us to compute the regulated type's equilibrium utility: ${ }^{8}$

$$
u_{R}=V\left(p_{R} \bar{l}, \bar{l}, p\right)=p^{-\frac{\gamma}{\gamma-1}}\left[p_{R}^{-\frac{\alpha}{1-\alpha}}-\frac{1}{\gamma} p_{R}^{-\frac{\gamma}{1-\alpha}}\right] .
$$

The rent $u_{R} / u_{N}$ earned by the regulated agents in relative utility terms is denoted by $J$. We have that

$$
J=\frac{\gamma p_{R}^{-\frac{\alpha}{1-\alpha}}-p_{R}^{-\frac{\gamma}{1-\alpha}}}{\gamma-1} .
$$

\footnotetext{
${ }^{8}$ It can be shown that $\frac{d u_{R}}{d p_{R}}>0$ at $p_{R}=1$. Implying there exist levels of regulation that make regulated people better-off.
} 


\section{Reform}

\subsection{Extensive reform}

Now consider a reform whereby the fraction of regulated sectors is reduced from $r$ to $r^{\prime}<r$. I will denote by $\Delta r=r-r^{\prime}$ the size of the reform. In order to compensate losers, the government transfers a lump-sum $T$ to each household $i$ such that $r^{\prime}<i \leq r$. This transfer is financed by a general proportional tax on labor income $\tau$. We want to know the conditions under which such a scheme allows to implement the reform in a Pareto-improving way. For this we need to compute the new equilibrium, taking into account the link between $\tau$ and $T$ implied by the government's budget constraint.

LEMMA $1-$ A. The new values of the price level and of employment (=output) in any sector $i$ are given by

$$
\begin{aligned}
p^{\prime} & =\left(r^{\prime} p_{R}^{-\frac{\alpha}{1-\alpha}}+1-r^{\prime}\right)^{-\frac{1-\alpha}{\alpha}}=p_{E}^{\prime} ; \\
l_{i} & =l_{N}^{\prime}=p^{\prime-\frac{1}{\gamma-1}}(1-\tau)^{\frac{1}{\gamma-1}}=l_{N E}^{\prime}, i>r^{\prime} \\
l_{i} & =\bar{l}^{\prime}=p_{R}^{-\frac{1}{1-\alpha}} p^{-\frac{1}{\gamma-1}}(1-\tau)^{\frac{1}{\gamma-1}}=\bar{l}_{E}^{\prime}, i \leq r^{\prime} .
\end{aligned}
$$

B. Nonregulated groups $(i>r)$ and nonderegulated groups $\left(i \leq r^{\prime}\right)$, weakly gain from the reform if and only if

$$
1-\tau \geq \frac{p^{\prime}}{p}
$$

C. Deregulated groups $\left(r^{\prime}<i \leq r\right)$ weakly gain from the reform if and only if

$$
T \geq p^{\prime-\frac{1}{\gamma-1}} \frac{\gamma-1}{\gamma}\left[\left(\frac{p^{\prime}}{p}\right)^{\frac{\gamma}{\gamma-1}} J-(1-\tau)^{\frac{\gamma}{\gamma-1}}\right],
$$

where $T$ is the equilibrium transfer level given by

$$
T=\frac{\tau(1-\tau)^{\frac{1}{\gamma-1}} p^{-\frac{1}{\gamma-1}-\frac{\alpha}{1-\alpha}}}{\Delta r} .
$$

D. Consequently, for any $r^{\prime}<r$, the reform can be implemented in a Pareto-improving way if and only if there exists some $\tau \in[0,1]$ such that (9) and (10) hold, for $T$ given by (11). 
Proof - See Appendix

Equation (9) implies that the nonregulated and nonderegulated groups are better-off provided the tax rate does not exceed a critical threshold

$$
\tilde{\tau}_{E}=1-p_{E}^{\prime} / p
$$

which is equal to their increase in pre-tax real income due to deregulated goods being cheaper. Such a tax rate need not be Pareto-optimal because it may lie on the wrong side of the "Laffer curve". The following proposition characterizes such situations:

PROPOSITION 1 - (i) There exists a unique tax rate $\hat{\tau}_{E} \in(0,1)$ which maximizes the utility of the deregulated agents, $u_{D}^{\prime}$, which is hump-shaped in $\tau$.

(ii) This tax rate is equal to

$$
\hat{\tau}_{E}=\frac{(\gamma-1)\left(p_{E}^{\prime-\frac{\alpha}{1-\alpha}}-\Delta r\right)}{\gamma p_{E}^{\prime-\frac{\alpha}{1-\alpha}}-(\gamma-1) \Delta r} .
$$

(iii)

Assume

$$
p \leq \gamma-r(\gamma-1)
$$

then

$$
\hat{\tau}_{E} \geq \tilde{\tau}_{E} \text { for all } r^{\prime} \leq r .
$$

(iv) Assume (13) is violated. Then there exists a unique $r_{c} \in(0, r)$ such that

$$
r^{\prime} \geq r_{c} \Leftrightarrow \hat{\tau}_{E} \geq \tilde{\tau}_{E}
$$

There exists a utility "Laffer curve" for the deregulated agents, which reflects the fact that tax receipts eventually fall with tax rates, and also the fact that, by assumption, their own income is taxable. Proposition 1 studies whether the limits to compensation for reform come from this Laffer curve as opposed to the participation constraint for nonderegulated agents, (43). If 
condition (13) holds, for any reform size, the deregulated agents are betteroff, the higher the tax rate as long as it satisfies (43). If (13) is violated, this property only holds if the reform is not too large. Otherwise, tax distortions make the deregulated agents worse-off as $\tau$ goes up beyond some level which strictly satisfies the nonderegulated agents' participation constraint.

We note that (13) is more likely to holds, the greater $\gamma$, i.e. the more inelastic labor supply is. Furthermore, since $p>1$, it is violated for $\gamma$ small enough. The smaller $\gamma$, the more distortionary taxes are, and the more likely it is that the limiting factor in compensating the losers is the Laffer curve as opposed to the requirement that taxes leave positive gains for nonderegulated agents. Nevertheless, even in that case one can show that at $\tau=\tilde{\tau}_{E}$ tax receipts are high enough to compensate the deregulated groups for their losses. Intuitively, situations where such a tax is highly distortionary and yields little revenues are also situations where the initial price distortion is highly distortionary (the distortion on the labor supply of nonregulated groups is by construction the same at $\tau=\tilde{\tau}_{E}$ ), implying a relatively low initial welfare. This is why an unfavorable position on the Laffer curve does not per se reduce the scope for compensation, although it leaves room for even more favorable reform packages. The next proposition shows that by picking a tax close enough to $\tilde{\tau}_{E}$ the reform can be implemented in a Paretoimproving way:

PROPOSITION 2 - All extensive structural reforms are viable in the sense that for any $r^{\prime} \leq r$ there exists $\bar{\tau}_{E} \in\left(0, \tilde{\tau}_{E}\right]$ such that the post-reform allocation Pareto-dominates the pre-reform one if and only if $\bar{\tau}_{E} \leq \tau \leq \tilde{\tau}_{E}$. Furthermore, if $\hat{\tau}_{E}<\tilde{\tau}_{E}$, all reforms such that $\hat{\tau}_{E}<\tau$ are Pareto-dominated by $\tau=\hat{\tau}_{E}$.

What is the interpretation of Proposition 2? For the nonregulated agents, the gains from reform (ignoring transfers) entirely depend on their net real wage, equal here to $(1-\tau) / p_{E}^{\prime}$, and that is also the case for labor supply. Therefore, the level of $\tau$ which entirely cancels their gains is the one that 
leaves their net real wage unchanged relative to the no reform case, and it also leaves their net labor supply unchanged. Setting $\tau$ at that level transfers all their utility gains from reform to the deregulated agents.

This argument also holds for the nonderegulated agents, but that is for general equilibrium reasons: Preferences are homothetic and the consumption ratio between any regulated good and any nonderegulated good is $p_{R}^{-\frac{1}{1-\alpha}}$. This quantity is unaffected by an extensive reform. At a tax rate which leaves labor supply and therefore production unchanged in nonregulated goods compared to the pre-reform case, the demand-determined level of output in any remaining regulated good must therefore also be the same as in the prereform case. Nonderegulated households then have the same pre-tax income as before the reform. They benefit from a lower aggregate price level but these benefits are taxed proportionally, exactly the same way as for nonregulated households. Consequently, they are left indifferent about reform at exactly the same tax rate as the nonregulated.

Therefore, at $\tau=\tilde{\tau}_{E}$ all the social gains from the reform are transferred to the deregulated. But these aggregate social gains are strictly positive both because the inefficient price dispersion between goods is reduced and because the labor supply of the deregulated agents, which was inefficiently low, goes up due to demand being reallocated in their favor (compare (41) with (6)).

In short: for distortions to prevent the reform from being implemented, compensatory taxes should reduce labor supply relative to the no reform case. But labor supply is unchanged at the tax level that leaves nonderegulated agents exactly indifferent, while it goes up for the deregulated.

\subsection{Intensive reform}

Now consider an intensive reform: instead of deregulating a fraction of the sectors, the price of all regulated sectors is reduced from $p_{R}$ to $p_{R}^{\prime}<p_{R}$. Again a proportional $\operatorname{tax} \tau$ is levied upon all incomes and a compensatory lump-sum transfer $T$ is paid to the deregulated groups. The new equilibrium is summarized by Lemma 2 : 
LEMMA $2-$ A. The new values of the price level and of employment (=output) in any sector $i$ are given by

$$
\begin{aligned}
p^{\prime} & =\left(r p_{R}^{\prime-\frac{\alpha}{1-\alpha}}+1-r\right)^{-\frac{1-\alpha}{\alpha}}=p_{I}^{\prime} ; \\
l_{i}^{\prime} & =l_{N}^{\prime}=p^{\prime-\frac{1}{\gamma-1}}(1-\tau)^{\frac{1}{\gamma-1}}=l_{I}^{\prime}, i>r \\
l_{i}^{\prime} & =\bar{l}^{\prime}=p_{R}^{\prime-\frac{1}{1-\alpha}} p^{-\frac{1}{\gamma-1}}(1-\tau)^{\frac{1}{\gamma-1}}=\bar{l}_{I}^{\prime}, i \leq r .
\end{aligned}
$$

B. Nonregulated groups $(i>r)$ weakly gain from the reform if and only if

$$
\tau \leq \tilde{\tau}_{I}=1-\frac{p_{I}^{\prime}}{p}
$$

C. Regulated groups $(i \leq r)$ weakly gain from the reform if and only if

$$
\tau(1-\tau)^{\frac{1}{\gamma-1}} p^{\prime-\frac{\alpha}{1-\alpha}} \geq r \frac{\gamma-1}{\gamma}\left(J-\left(\frac{p(1-\tau)}{p^{\prime}}\right)^{\frac{\gamma}{\gamma-1}} J^{\prime}\right)\left(\frac{p^{\prime}}{p}\right)^{\frac{\gamma}{\gamma-1}}
$$

where

$$
J^{\prime}=\frac{\gamma p_{R}^{\prime-\frac{\alpha}{1-\alpha}}-p_{R}^{\prime-\frac{\gamma}{1-\alpha}}}{\gamma-1} .
$$

D. Consequently, for any $p_{R}^{\prime}<p_{R}$, the reform can be implemented in a Pareto-improving way if and only if there exists some $\tau \in[0,1]$ such that (14) and (15) hold, with at least one strict inequality.

It is again the case that the (partially) deregulated group's utility is humpshaped in $\tau$. The set of Pareto-optimal tax rates is therefore either $\left[0, \tau_{\max }\right]$, or $\left[0, \tilde{\tau}_{I}\right]$ depending on whether $\tau_{\max }$ is larger or smaller than $\hat{\tau}$.

Finally, we can show that an intensive reform is always viable. Again, the proof rests on showing that picking $\tau=\tilde{\tau}_{I}$ yields net gains for the deregulated groups. Therefore, Proposition 2 holds in the case of an intensive reform too.

\section{PROPOSITION $3-$}

(i) There exists a unique tax rate $\hat{\tau}_{I} \in(0,1)$ which maximizes the utility of the regulated agents, $u_{R}^{\prime}$, which is hump-shaped in $\tau$. 
(ii) This tax rate is equal to

$$
\hat{\tau}_{I}=\frac{(\gamma-1)\left(p_{I}^{\prime-\frac{1}{1-\alpha}}-r J^{\prime}\right)}{\gamma p_{I}^{\prime-\frac{1}{1-\alpha}}-(\gamma-1) r J^{\prime}} .
$$

(iii) There exists $\bar{\tau}_{I} \in\left(0, \tilde{\tau}_{I}\right]$ such that the post-reform allocation Paretodominates the pre-reform one if and only if $\bar{\tau}_{I} \leq \tau \leq \tilde{\tau}_{I}$.

(iv) If $\hat{\tau}_{I}<\tilde{\tau}_{I}$ then all reforms such that $\hat{\tau}_{I}<\tau$ are Pareto-dominated by $\tau=\hat{\tau}_{I}$.

\section{Some more general results}

In this section I consider a more general framework: utility is still linear in aggregate consumption (hence homothetic) but not isoelastic. There is no restriction on the shape of regulation nor on the structure of reform (although I only consider small reforms). I assume that tax rates can be differentiated across groups, implying that the only distortions come from labor supply, as opposed to informational rents. There are three main results: First, aggregate welfare goes up if and only if a weighted average of labor supply across regulated sectors goes up (Proposition 4). Second, despite the tax distortions, any vector of labor supply increments in the regulated sector can be implemented along with a Pareto-improving schedule of (distortionary) taxes and (lump-sum) transfers (Proposition 6). Third, this implementation is a deregulation only under some conditions, spelled out in Proposition 7.

\subsection{Preliminaries}

Notations: There are $q=n+r$ goods, indexed by $i=1, \ldots q$. A vector will be denoted by lower case, bold letters, $\mathbf{x}$ and its components by $x_{i}$. In particular, 1 denotes a vector whose elements are all equal to 1 . A matrix will be denoted by an upper-case, bold, $\mathbf{M}$ and its components by $m_{i j}$. These conventions are extended to functions, for example for a collection of scalar functions $\left(f_{1}, f_{2}, \ldots\right), \mathbf{f}(\mathbf{x})$ is a vector whose $i$ 'th element is $f_{i}\left(x_{1}, \ldots, x_{q}\right)$. Similarly, for 
any scalar function $f$ and vector $\mathbf{x}, f(\mathbf{x})=\left(f\left(x_{1}\right), f\left(x_{2}\right), \ldots\right)^{T}$. By definition, the gradient $\boldsymbol{\nabla} \mathbf{f}$ is a matrix whose generic element is $\partial f_{i} / \partial x_{j}$. If $f$ is a scalar, $\nabla f$ is its gradient, defined as a line vector to remain consistent with the preceding definition. For any two vectors $\mathbf{x}, \mathbf{y}$, their scalar product is denoted by $\langle\mathbf{x}, \mathbf{y}\rangle=\sum_{i} x_{i} y_{i}$. For any $q$-vector $\mathbf{x}$, I will denote by $\mathbf{x}_{N}=\left(x_{1}, \ldots, x_{n}\right)$ the $n$-vector made of its first $n$ components and by $\mathbf{x}_{R}=\left(x_{n+1}, \ldots, x_{q}\right)$ the $r$-vector made of the remaining values. For any two commensurate vectors, $\mathbf{x}$ and $\mathbf{y}, \mathbf{z}=\mathbf{x} \bullet \mathbf{y}$ denotes their element by element product, i.e. $z_{i}=x_{i} y_{i}$. Element by element division is denoted by $\div$, and in particular for any three vectors $\mathbf{x}, \mathbf{y}, \mathbf{z}, z_{i} \neq 0,\langle\mathbf{x}, \mathbf{y}\rangle=\langle\mathbf{x} \bullet \mathbf{z}, \mathbf{y} \div \mathbf{z}\rangle$.

There is a continuum of agents of total mass 1 , who have the same utility function but differ by skills. For each $i$, a mass $1 / q$ of agents have skills specific to sector $i$ and can only work in that sector. Utility is

$$
U(\mathbf{c}, l)=u(\mathbf{c})-v(l)
$$

where $v^{\prime}, v^{\prime \prime}>0$ and $u$ is concave and homogeneous of degree one. This assumption guarantees that lump-sum transfers or taxes, when available, would not change labor supply. Therefore, any reform which raises total utility can be implemented in Pareto-improving way if lump-sum taxes and transfers are available. I assume $u$ satisfies the following

Let $p_{i}$ be the price of good $i$ and $R$ the consumer's expenditure. The expenditure function is denoted by

$$
c_{i}=R \psi_{i}(\mathbf{p})
$$

In particular,

$$
\langle\mathbf{p}, \boldsymbol{\psi}(\mathbf{p})\rangle=1, \forall \mathbf{p}
$$

I normalize the aggregate hedonic price level to 1 , implying that $u=R$, i.e. utility can be rewritten as $R-v(l)$. Consequently labor supply is

$$
l=\lambda(w)
$$


where $\lambda=v^{\prime-1}$ and $w$ is the real wage.

Sectors are either regulated or nonregulated. I denote by $N=\{1, \ldots, n\}$ the set of nonregulated sectors (or, rather, their indices) and $R=\{n+1, \ldots, q\}$ the set of regulated sectors. In deregulated sectors, the price adjusts to ensure competitive equilibrium. In regulated sectors, the price is fixed by law above the competitive level, so that output is determined by demand and supply is rationed.

Production $y_{i}$ in sector $i$ only uses the specific labor input $l_{i}$ and unit labor requirement is equal to 1

$$
y_{i}=l_{i}
$$

The pre-reform allocation of resources is then determined by the following set of equations

$$
\begin{aligned}
\mathbf{l} & =Y \boldsymbol{\psi}(\mathbf{p}) \\
\mathbf{l}_{N} & =\lambda\left(\mathbf{p}_{N}\right) \\
u(\boldsymbol{\psi}(\mathbf{p})) & =1 .
\end{aligned}
$$

The unknows are (i) $Y$, aggregate GDP, (ii) $\left(p_{1}, \ldots, p_{n}\right)$, the nonregulated prices, (iii) $\mathbf{l}$, the vector of employment (=output) in each sector. These are $q+n+1$ unknowns. The corresponding equations are (i) that output equals demand in all sectors (18), (ii) that output equals supply in all nonregulated sectors (19), and (iii) that the aggregate price level is normalized to 1 (20). By construction, from (18) and (17) it is always true that total income equals total expenditure, i.e. $Y=\langle\mathbf{p}, \mathbf{l}\rangle$. The distribution of income is summarized by

$$
\mathbf{R}=\mathbf{p} \bullet \mathbf{l}
$$

I will denote by

$$
s_{i}=p_{i} \psi_{i}(\mathbf{p})
$$

the income share of sector $i$. 
For prices to be above their equilibrium value in regulated sectors, we need that $v^{\prime}\left(l_{i}\right)<p_{i}$ for $i \in R$. Let

$$
\omega_{i}=1-\frac{v^{\prime}\left(l_{i}\right)}{p_{i}} \in[0,1) .
$$

Clearly, $\omega_{i}$ is a measure of the regulatory distortion in sector $i$. The smaller $\omega$, the closer the sector is to competitive equilibrium. We have that $\omega_{i}=0$ for $i \in N$.

\subsubsection{Reforms}

I now consider a perturbation of the preceding equilibrium, called a reform. It is useful to consider various reform definitions:

1. A pure structural reform (PSR) is a change in the set of regulated prices from $\left(p_{n+1}, \ldots, p_{q}\right)$ to $\left(p_{n+1}+d p_{n+1}, \ldots, p_{q}+d p_{q}\right)$, i.e. $\mathbf{p}_{R}$ is replaced by $\mathbf{p}_{R}+\mathbf{d p}_{R}$.

2. A structural reform with fiscal adjustment (SRFA) consists of three items: (i) a change in the set of regulated prices from $\mathbf{p}_{R}$ to $\mathbf{p}_{R}^{\prime}=\mathbf{p}_{R}+\mathbf{d} \mathbf{p}_{R}$, (ii) introducing (possibly negative) proportional taxes on labor (or production), income in each sector at a small rate $d \tau_{i}$, (iii) paying a (possibly negative) small lump-sum transfer to each individual in sector $i, d T_{i}$. These instruments must satisfy the government budget constraint

$$
\langle\mathbf{s}, \mathbf{d} \tau\rangle Y=\langle\mathbf{1}, \mathbf{d T}\rangle
$$

Such a reform $\rho$ is described by the triplet $\rho=\left(\mathbf{d p}_{R}, \mathbf{d} \tau, \mathbf{d T}\right)$. An SRFA is the most general case we consider.

3. A structural reform with side transfers (SRST) is an SRFA such that $\mathbf{d} \boldsymbol{\tau}=\mathbf{0}$. Consequently, the budget constraint is just

$$
\langle\mathbf{1}, \mathbf{d T}\rangle=0 .
$$

4. A feasible structural reform (FSR) is an SRFA such that $\mathbf{d T} \geq \mathbf{0}$. That is, we allow for proportional taxes and subsidies, as well as lump-sum transfers, but rule out lump-sum taxes. 
The post-reform equilibrium allocation of labor, price vector, and GDP level solves the following conditions

$$
\begin{aligned}
\mathbf{l}^{\prime} & =Y \boldsymbol{\psi}\left(\mathbf{p}^{\prime}\right) \\
\mathbf{l}_{N}^{\prime} & =\lambda\left(\mathbf{p}_{N}^{\prime} \bullet\left(\mathbf{1}_{N}-\mathbf{d} \boldsymbol{\tau}_{N}\right)\right) \\
u\left(\boldsymbol{\psi}\left(\mathbf{p}^{\prime}\right)\right) & =1,
\end{aligned}
$$

where the new values are determined by primes. The new distribution of income is

$$
\mathbf{R}^{\prime}=\mathbf{p}^{\prime} \bullet \mathbf{l}^{\prime} \bullet(\mathbf{1}-\mathbf{d} \tau)+\mathbf{d T}=Y \mathbf{s}^{\prime} \bullet(\mathbf{1}-\mathbf{d} \boldsymbol{\tau})+\mathbf{d} \mathbf{T}
$$

The irrelevance of tax distortions in regulated sectors A key feature of the analysis and of the proofs is that proportional taxes are only distortionary for nonregulated sectors. In regulated sectors, supply is constrained by demand. Therefore activity is not reduced by a marginal proportional tax. As a result, the feasibility constraint $d T_{i} \geq 0$ is irrelevant for regulated sectors. Any lump-sum tax can be replaced by a proportional tax, with no difference for the allocation of resources. We can give formal content to this observation:

DEFINITION 1 - Let $\rho_{0}=\left(\mathbf{d p}_{R 0}, \mathbf{d} \tau_{0}, \mathbf{d} \mathbf{T}_{0}\right)$ and $\rho_{1}=\left(\mathbf{d} \mathbf{p}_{R 1}, \mathbf{d} \tau_{1}, \mathbf{d} \mathbf{T}_{1}\right)$ be two SRFAs. They are equivalent $\left[\rho_{0} \sim \rho_{1}\right]$ if and only if

$$
\begin{aligned}
\mathbf{l}_{0}^{\prime} & =\mathbf{l}_{1}^{\prime} \\
\mathbf{R}_{0}^{\prime} \boldsymbol{\psi}\left(\mathbf{p}_{0}^{\prime}\right)^{T} & =\mathbf{R}_{1}^{\prime} \boldsymbol{\psi}\left(\mathbf{p}_{1}^{\prime}\right)^{T}
\end{aligned}
$$

That is, the post-reform labor supply and consumption vector of each group is unchanged, and so is welfare. It will be also useful to define production-equivalence:

DEFINITION 2 - Let $\rho_{0}=\left(\mathbf{d p}_{R 0}, \mathbf{d} \tau_{0}, \mathbf{d} \mathbf{T}_{0}\right)$ and $\rho_{1}=\left(\mathbf{d} \mathbf{p}_{R 1}, \mathbf{d} \boldsymbol{\tau}_{1}, \mathbf{d} \mathbf{T}_{1}\right)$ 
be two SRFAs. They are production-equivalent $\left[\rho_{0} \approx \rho_{1}\right]$ if and only if

$$
\begin{aligned}
\mathbf{l}_{0}^{\prime} & =\mathbf{l}_{1}^{\prime}, \\
\mathbf{p}_{0}^{\prime} & =\mathbf{p}_{1}^{\prime} .
\end{aligned}
$$

Clearly, if two reforms are production-equivalent and deliver the same distribution of income $\left(\mathbf{R}_{0}^{\prime}=\mathbf{R}_{1}^{\prime}\right)$, then they are equivalent.

LEMMA 3 - Let $\rho_{0}=\left(\mathbf{d p}_{R 0}, \mathbf{d} \tau_{0}, \mathbf{d} \mathbf{T}_{0}\right)$ and $\rho_{1}=\left(\mathbf{d} \mathbf{p}_{R 1}, \mathbf{d} \tau_{1}, \mathbf{d} \mathbf{T}_{1}\right)$ be two SRFAs. Assume that $\mathbf{d} \mathbf{p}_{R 0}=\mathbf{d p}_{R 1}, \mathbf{d} \boldsymbol{\tau}_{N 0}=\mathbf{d} \boldsymbol{\tau}_{N 1}, \mathbf{d} \mathbf{T}_{N 0}=\mathbf{d} \mathbf{T}_{N 1}$, and $\mathbf{d} \mathbf{T}_{R 0}-Y \mathbf{s}_{R 0} \bullet \mathbf{d} \boldsymbol{\tau}_{R 0}=\mathbf{d} \mathbf{T}_{R 1}-Y \mathbf{s}_{R 1} \bullet \mathbf{d} \boldsymbol{\tau}_{R 1}$. Then $\rho_{0} \sim \rho_{1}$.

Proof - Clearly, the system (23-25) is the same under both reforms. Therefore, the equilibrium set of prices and allocation of labor is identical, i.e. $\mathbf{d p}_{0}=\mathbf{d p}_{1}, \mathbf{d l}_{0}=\mathbf{d l}_{1}$. Furthermore, by construction, $\mathbf{R}_{0}^{\prime}=\mathbf{R}_{1}^{\prime}$. Hence both conditions in Definition 1 hold. QED.

Therefore, everything takes place as if lump-sum taxes were available for regulated sectors. For $i \in R$, I denote by $d \tilde{T}_{i}=d T_{i}-Y s_{i} d \tau_{i}$ the net income transfer to group $i$. Then

LEMMA 4 - For any SRFA $\rho$ such that $\mathbf{d T}_{N} \geq 0$, there exists an FSR $\tilde{\rho}$ such that $\tilde{\rho} \sim \rho$.

Proof - For any $i \in R$ such that $d T_{i}<0$, replace $d T_{i}$ by 0 and $d \tau_{i}$ by $-d \tilde{T}_{i} /\left(Y s_{i}\right)$. Then apply Lemma 3 .

The case for Pareto-improving structural reforms In this subsection I provide some basic results on the conditions for structural reforms to be welfare-improving. My starting point is utilitarian social welfare, which is defined as

$$
W=\sum_{i} U\left(\mathbf{c}_{i}, l_{i}\right)=\sum_{i} R_{i}-v\left(l_{i}\right)=Y-\langle\mathbf{1}, v(\mathbf{l})\rangle
$$

PROPOSITION 4 - Consider an SRFA 
(i) The effect on utilitarian social welfare is

$$
\frac{d W}{Y}=\langle\mathbf{s} \bullet \boldsymbol{\omega}, \mathbf{d l} \div \mathbf{l}\rangle
$$

Consequently, aggregate social welfare goes up if and only if

$$
\langle\mathrm{s} \bullet \omega, \mathrm{dl} \div \mathrm{l}\rangle>0
$$

(ii) The change in output is

$$
\frac{d Y}{Y}=\langle\mathbf{s}, \mathbf{d} \mathbf{l} \div \mathbf{l}\rangle
$$

(iii) The change in income distribution $(\mathbf{R}=\mathbf{s} Y)$ is

$$
\mathrm{dR} \div \mathbf{R}=\mathrm{dp} \div \mathbf{p}+\mathrm{dl} \div \mathbf{l}-\mathrm{d} \tau+\mathrm{dT} \div \mathbf{R}
$$

(iv) For any PSR such that (27) holds, there exists a Pareto-improving production-equivalent SRST.

Proof - See Appendix.

Proposition 4 tells us that regardless of the accompanying fiscal scheme, aggregate social welfare goes up if and only if a weighted average of employment growth in regulated sectors is positive, with weights proportional to the product between their share in GDP and their distortion index. Claim (iv) is just a verification of the standard result that the utilitarian and Pareto criteria coincide if utility is linear in consumption.

I now show that Pareto-improving feasible structural reforms are always possible, despite that lump-sum transfers can only be financed by distortionary taxes. The argument rests upon the same device as in the preceding section, i.e. imposing a proportional tax on the deregulated that leaves them indifferent about the reform, or equivalently such that their net after tax real wage is unchanged.

DEFINITION 3 - An SRFA is N-neutral if and only if

$$
\mathbf{d T}_{N}=\mathbf{0}
$$


and

$$
\mathbf{d} \tau_{N}=\mathbf{d p}_{N} \div \mathbf{p}_{N}
$$

An N-neutral reform taxes away any welfare gains made by a nonregulated group, by imposing a proportional tax equal to the increase in their real wage (i.e. the price of their product). In particular, this implies that their labor supply, and consequently their employment level, is unchanged, i.e. $\mathbf{d l}_{N}=\mathbf{0}$.

PROPOSITION 5 - Assume an SRFA $\rho_{0}$ is N-neutral and satisfies (27). Then there exists an N-neutral FRS $\rho_{1}$ such that (i) $\rho_{0} \approx \rho_{1}$, and (ii) $\rho_{1}$ is Pareto-improving.

Proof - See Appendix

In other words, if an N-neutral reform satisfies the utilitarian criterion, I can construct a feasible reform which has the same effect on the productive allocation of resources and is Pareto-optimal. Note that whether or not a reform is $\mathrm{N}$-neutral depends on whether the endogenous equilibrium prices satisfy (30). It is not a priori obvious that an N-neutral reform exists. But if it does, Proposition 5 tells us that it can be implemented in a Paretoimproving way. The reason is that if (27) holds, the aggregate utility gain of the regulated agents is strictly positive (since that of the nonregulated is zero by construction), and Lemma 4 tells us that utility can be freely transferred between them in a feasible way.

Consequently, to establish the existence of Pareto-improving, feasible structural reforms, it is enough to show that an N-neutral reform which satisfies (27) can be constructed.

PROPOSITION 6 - For any r-vector $\mathbf{d z}$ there exists an N-neutral SRFA such that $\mathbf{d l}_{R}=\mathbf{d z}$.

Proof - See Appendix.

Corollary - There exists a Pareto-improving structural reform.

Proposition 6 tells us that we can solve the inverse problem, that is, pick a reform which delivers any arbitrary vector of employment growth for the 
regulated sector, and make sure it is N-neutral. Since the choice of $\mathbf{d l}_{R}$ is arbitrary, we can always pick that vector so that there are aggregate welfare gains, i.e. so that (27) holds. This will be the case, in particular, if $\mathbf{d l}_{R} \geq \mathbf{0}$ with at least one strict inequality. In this case, since the reform is N-neutral, $\mathbf{d l}_{N}=0$, so that we also have $d Y>0$ by (28). The corollary follows from Proposition 5, which tells us that we can then always design the tax treatment of the deregulated so as to make each of them better-off in a feasible way.

While Propositions 5 and 6 tell us that many structural reforms exist that are both feasible and Pareto-improving, they are mute about the structure of those reforms. They need not be deregulations in the sense that all price controls are loosened: Regulation could in principle be tightened for some goods, i.e. $d p_{i}>0$.

The conditions for deregulation to be implementable in a Pareto-improving way are far more stringent. The following Proposition provides a sufficient condition.

PROPOSITION 7 - Let

$$
\begin{aligned}
s_{R} & =\left\langle\mathbf{s}_{R}, \mathbf{1}\right\rangle, \\
\sigma=\min _{i} \sigma_{i} & =-\frac{p_{i}}{\psi_{i}}[\boldsymbol{\nabla} \boldsymbol{\psi}]_{i i}>0,
\end{aligned}
$$

and

$$
\eta=\max _{i, j, i \neq j}\left|\frac{p_{j}}{\psi_{i}}[\boldsymbol{\nabla} \boldsymbol{\psi}]_{i j}\right| \geq 0
$$

Consider a nonzero r-vector of price reductions $\mathbf{d x} \geq \mathbf{0}$. Let $x_{m}=\max \mathbf{d x}>\mathbf{0}$, $\bar{x}_{Y}=\left\langle\mathbf{s}_{R}, \mathbf{d x}\right\rangle / s_{R}>0$, and $\sigma_{R}=\left\langle\mathbf{s}_{R}, \boldsymbol{\sigma}_{R} \bullet \mathbf{d} \mathbf{x}\right\rangle /\left\langle\mathbf{s}_{R}, \mathbf{d x}\right\rangle>0$.

Assume

$$
\eta<\frac{1}{q-1} \min \left(\frac{1-s_{R}}{2} \sigma, \frac{\bar{x}_{Y}}{x_{m}} \sigma_{R}\right)
$$

Then (i) there exists an N-neutral SRFAs such that $\mathbf{d} \mathbf{p}_{R} \div \mathbf{p}_{R}=-\mathbf{d x}$ and

(ii) These reforms are such that $\mathbf{d l}_{R}>0$, implying that they satisfy (27) and (28). 
Proof - See Appendix.

This proposition tells us that (i) if the price cross-elasticities of demand (whose maximum absolute value across pairs of goods is $\eta$ ) are small enough relative to the own price elasticities (whose minimum absolute value across all goods is $\sigma$, and whose income share weighted average across regulated goods is $\sigma_{R}$ ); and (ii) if the structural reform is not too unbalanced, in the sense that the maximum reduction in a regulated price $x_{m}$ is not too large relative to its income share weighted average counterpart $\bar{x}_{Y}$, then an N-neutral SRFAs reform exists which implements the planned structural reform, and it is such that employment grows in all regulated sectors. In turn, this implies that it satisfies (27), so that by Proposition 5 we know that the planned structural reform can be implemented in a Pareto-improving fashion.

Note that in the case of isoelastic utility, studied in the preceding section, $\eta=0$, so that Proposition 7 applies.

Also, for the reform to be implemented in a Pareto-improving way, we do not need that $\mathbf{d l}_{R}>0$. Lemma A4 in the Appendix provides a weaker condition than (31), with analogous properties, for the N-neutral reform to satisfy $(27)$.

Intuitively, if cross-elasticities are too large, upon deregulation the increase in the relative price of some nonregulated good (resp. fall in the price of some regulated good) may reduce total demand for a complement (resp. substitute) regulated good by enough so that employment would fall. If distortions are particularly large in that sector, total social welfare could well be reduced.

\section{Some counter-examples}

I now discuss some counter-examples where a Pareto-improvement is not possible. In the first example, tax rates cannot be differentiated across groups, and the indexation rules of regulated prices are such that the tax rate that leave consumers indifferent about the reform no longer coincide between non- 
regulated and nonderegulated groups. In the second example, utility differs across agents in a non-observable way. Some consumers gain more than others from reform because they consume a greater share of deregulated goods. Informational rents would have to be transferred to them (in the form of a lower overall tax rate) so as to make all consumers better-off, which may deliver too low tax receipts to compensate the losers. If these have veto power, reform may in turn fail to get a majority support.

\subsection{Indexation on the aggregate price level}

In the second-best world we consider, the welfare effects of a given partial reform depend on the specifics of regulation. The way regulation is specified has a general equilibrium effect on the distribution of gains from the reform. In particular, the indexation rule for the prices of the regulated sectors matters. Section 3, when considering an extensive reform, I have assumed that the price of the regulated sectors is automatically indexed on the price of the unregulated sectors. This generates a built-in mechanism through which the nonderegulated sectors benefit from the reform through a higher purchasing power, since the price of unregulated sectors (and therefore their own price) goes up relative to the aggregate price level when there is a reform ${ }^{9}$. I have shown that for any given tax rate, the utility gains of the nonderegulated groups are then proportional to those of the regulated groups, implying that the same tax rate leaves both groups indifferent between the reform and the status quo. In other words, it is possible to finance a compensatory transfer by a uniform proportional tax rate on all incomes, in a way that does not leave any rent to the groups that are not directly affected by the reform. Whenever the regulated price is indexed on the aggregate price level, though, this conclusion no longer holds. As the price of the nonderegulated groups is indexed on the aggregate price level, their real wage is unchanged by the

\footnotetext{
${ }^{9}$ The indexation rule is irrelevant in the case of intensive reform, since there is only one relative price in the economy we consider. However, under extensive reform, relative prices may change along two dimensions, since there are three groups that are differently affected by the reform: nonregulated, deregulated, nonderegulated.
} 
reform. Their potential gains only come from the fact that they work more, due to the general equilibrium effect of the reform upon labor demand. Since their gains are smaller than under the indexation rule considered in Section 3 , it turns out that the maximum tax rate that prevents them from being net losers is lower than its counterpart for the nonregulated groups. Unless tax rates can be differentiated among groups ${ }^{10}$, these groups must therefore earn rents compared to the nonderegulated ones, which reduces the amount that can be transferred to the losers of the reform. As a result, a Pareto-improving reform becomes impossible under some configurations.

I now describe how the equilibrium is changed by this new indexation rule and discuss its consequences for the viability of reform.

It is now natural to normalize the aggregate price level, instead of the nonregulated price, to 1 . As a result, $p_{R}$ can again be treated as fixed. The nonregulated price $p_{N}$, for any given $r$, solves

$$
r p_{R}^{-\frac{\alpha}{1-\alpha}}+(1-r) p_{N}^{-\frac{\alpha}{1-\alpha}}=1
$$

Note that since $p_{R}>1, p_{N}<1$. Furthermore, $\partial p_{N} / \partial r<0$. The greater the scope of regulation, the lower the price (i.e. the real wage), of the nonregulated groups.

Again, I consider an extensive reform with the same features as above. $r$ falls to $r^{\prime}=r-\Delta r$. A proportional tax $\tau$ is levied on all incomes. The proceeds are rebated to the groups whose indexed falls between $r^{\prime}$ and $r$ in a lump-sum, uniform fashion.

We can then prove the following

LEMMA 5 - A. The new values of the price of nonregulated goods and

\footnotetext{
${ }^{10}$ Here there is no a priori reason why tax rates could not be differentiated across groups, as different groups produce different goods. Still, policy may be constrained by the complexity of the compensatory tax scheme. Also, although this is outside the scope of this model, uniform tax rates may be considered as especially legitimate in the presence of disagreements about the distributional effects of the reform.
} 
of employment (=output) in any sector $i$ are given by

$$
\begin{aligned}
p_{i}^{\prime} & =p_{N}^{\prime}=\left(\frac{1-r^{\prime} p_{R}^{-\frac{\alpha}{1-\alpha}}}{1-r^{\prime}}\right)^{-\frac{1-\alpha}{\alpha}}, i>r^{\prime} ; \\
l_{i} & =l_{N}^{\prime}=\left(p_{N}^{\prime}(1-\tau)\right)^{\frac{1}{\gamma-1}}, i>r^{\prime} \\
l_{i} & =\bar{l}^{\prime}=p_{N}^{\prime \frac{1}{\gamma-1}+\frac{1}{1-\alpha}} p_{R}^{-\frac{1}{1-\alpha}}(1-\tau)^{\frac{1}{\gamma-1}}, i \leq r^{\prime} .
\end{aligned}
$$

B. Nonregulated groups $(i>r)$ weakly gain from the reform if and only if

$$
1-\tau \geq \frac{p_{N}}{p_{N}^{\prime}}
$$

C. Nonderegulated groups $\left(i \leq r^{\prime}\right)$ weakly gain if and only if

$$
1-\tau \geq \frac{p_{N}}{p_{N}^{\prime}}\left(\frac{J}{J^{\prime}}\right)^{\frac{\gamma-1}{\gamma}}
$$

where

$$
\begin{aligned}
J & =\frac{u_{R}}{u_{N}}=\frac{\gamma\left(p_{R} / p_{N}\right)^{-\frac{\alpha}{1-\alpha}}-\left(p_{R} / p_{N}\right)^{-\frac{\gamma}{1-\alpha}}}{\gamma-1} \\
J^{\prime} & =\frac{u_{R}^{\prime}}{u_{N}^{\prime}}=\frac{\gamma\left(p_{R} / p_{N}^{\prime}\right)^{-\frac{\alpha}{1-\alpha}}-\left(p_{R} / p_{N}^{\prime}\right)^{-\frac{\gamma}{1-\alpha}}}{\gamma-1}
\end{aligned}
$$

D. Deregulated groups $\left(r^{\prime}<i \leq r\right)$ weakly gain from the reform if and only if

$$
\tau(1-\tau)^{\frac{1}{\gamma-1}} p_{N}^{\frac{1}{\gamma-1}+\frac{1}{1-\alpha}} \geq \Delta r \frac{\gamma-1}{\gamma} p_{N}^{\frac{\gamma}{\gamma-1}}\left[J-\left(\frac{p_{N}^{\prime}(1-\tau)}{p_{N}}\right)^{\frac{\gamma}{\gamma-1}}\right] .
$$

Proof - See Appendix.

The effect of the reform on the relative rent of the regulated (which was unchanged under extensive reform in the analysis of section 3 except of course for the deregulated) can be obtained by examining (38) and (39). Typically, the regulated's rent $J$ will be locally increasing in $p_{R} / p_{N}$. Otherwise, $p_{R} / p_{N}$ is too high, in that regulated groups would gain from being less regulated. Therefore, since $p_{N}^{\prime}>p_{N}, J^{\prime}<J$. The reform reduces the utility rent of the 
regulated groups, due to the mechanical indexation of $p_{R}$ on the CPI. That is, $p_{N}$ goes up while $p_{R}$ is unchanged - nonderegulated groups tend to gain less from the reform than nonregulated ones. Consequently, the former accept the reform for lower tax rates than the latter. That is, (37) is more stringent than (36) as long as $J^{\prime}<J$. Unless taxes can be differentiated by groups, the nonregulated must gain enough from the reform for the nonderegulated to support it. These rents reduce the maximum possible value of $\tau$, which in turn makes it more likely that $T$ falls short of the level necessary to compensate losers. Indeed, an analytical result can be proved:

PROPOSITION 8 - There exists $\bar{p}_{R}>1$ such that for any $p_{R} \in\left(1, \bar{p}_{R}\right)$, the only viable reform is $r^{\prime}=0$.

Full reform remains viable here: As no nonderegulated sector remains, indexation becomes irrelevant and no rent has to be paid. Therefore the results of section 3 apply. For any partial reform, however, regardless of its scope, a Pareto-improvement is impossible if regulation is initially not too tight.

To complete this section, I provide some numerical simulations. Table 1 depicts the minimum value of $p_{R}$ below which reform cannot be implemented, denoted by $p_{R c}$, for various values of $\alpha, \gamma$ and $r$ and two types of reform: a near complete reform where $\Delta r \approx r$ and a marginal reform where $\Delta r \approx$ 0 . I also report the maximum value of $p_{R}, p_{R m}$, beyond which the rent of the regulated workers $J$, falls with $p_{R}$. This gives us an upper bound for reasonable values of $p_{R}{ }^{11}$

\footnotetext{
${ }^{11}$ The derivative of $J$ with respect to $z=p_{R} / p_{N}$ is equal to $\frac{\gamma}{(1-\alpha)(\gamma-1)}\left[z^{-\frac{\gamma}{1-\alpha}-1}-\alpha z^{-\frac{1}{1-\alpha}}\right]$. Thus $J$ reaches its maximum at $z=\alpha^{-\frac{1-\alpha}{\gamma-\alpha}}$ for $\alpha>0$, while $d J / d z$ is always positive for $\alpha \leq 0$. In the case where $\alpha>0$, eliminating $p_{N}$ between this condition and (32) we get that

$$
p_{R m}=\left(r+(1-r) \alpha^{-\frac{\alpha}{\gamma-\alpha}}\right)^{\frac{1-\alpha}{\alpha}} .
$$

It is not rational for regulated workers to collectively support a price greater than $p_{R m}$. Indeed as their utility is $u_{N} J$ and $u_{N}$ falls with $p_{R}$, their utility is maximum for some $p_{R}<p_{R m}$. There is no closed form solution, however, for that value.
} 


\begin{tabular}{llllll}
\hline \hline$\alpha$ & $\gamma$ & $r$ & $\Delta r$ & $p_{R m}$ & $p_{R c}$ \\
\hline 0.3 & 1.2 & 0.2 & $\approx 0$ & 2.17 & 1.18 \\
& & & $\approx 0.2$ & & 1.2 \\
\hline 0.3 & 1.2 & 0.5 & $\approx 0$ & 1.67 & 1.06 \\
& & 0.5 & $\approx 0.5$ & & 1.07 \\
\hline 0.8 & 1.2 & 0.2 & $\approx 0$ & 1.09 & 1.05 \\
& & & $\approx 0.2$ & & 1.05 \\
\hline-2 & 1.2 & 0.2 & $\approx 0$ & $\infty$ & 1.42 \\
& & & $\approx 0.2$ & & 1.47 \\
\hline 0.3 & 2 & 0.2 & $\approx 0$ & 1.5 & 1.15 \\
& & & $\approx 0.2$ & & 1.17 \\
\hline \hline
\end{tabular}

$\overline{\text { Table } 1 \text { - Numerical simulation result }}$ for the critical regulated price $p_{R c}$.

Table 1 suggests that if rents cannot be eliminated by discretionary taxation, it is not difficult to end up in a situation where consensus over a reform is impossible (unless this reform is complete). For example, for $\alpha=0.3, \gamma=1.2, r=0.2, p_{R}=1.1$, and $r^{\prime}=0.1$, the maximum tax rate that can be imposed upon the nonderegulated to spare them losses is $\tau=0.7 \%{ }^{12}$ The reform, while leaving the nonderegulated indifferent, raises the welfare of the nonregulated by $3.8 \%$ and reduces that of the deregulated by $10.5 \%$. Despite that employment grows by $5 \%$ and GDP grows by $4 \%$, aggregate social welfare only goes up by $1.2 \%$. This is small compared to the redistributive effects of the reform ${ }^{13}$.

\section{$5.2 \quad$ Heterogeneous preferences}

If preferences are heterogeneous and compensatory taxes cannot be indexed on them, then Pareto-improving reform may be impossible. Agents who benefit less from the reform because they consume less of the deregulated goods can only be better-off if they pay lower taxes. This in turn delivers rents to those who benefit more from the reform, which makes it impossible to design it in an N-neutral way. Clearly, if some groups in the population

\footnotetext{
${ }^{12}$ In contrast, the value of $\tau$ which maximizes the welfare of the deregulated is $\tau_{\max }=$ $15 \%$.

${ }^{13}$ For a paper where trade liberalization may have large negative effects on skill groups with sector-specific labor, see Saint-Paul (2007).
} 
do not consume the deregulated goods at all, for example, then (assuming general equilibrium effects are zero) Pareto-improvement is possible only if those can be identified and exempted from compensatory taxation.

In such a world, how many people gain from reform is a more relevant question than Pareto-optimality, which may be elusive. Below I propose two examples, in which I assume that the tax rate cannot be differentiated by preference groups. In Example 1 reform can be designed so that a vast majority of agents gains, in Example 2 it is far more difficult to implement it even so as to get a majority of winners, unless one gives up compensating $\operatorname{losers}^{14}$.

\subsubsection{Example 1}

People only consume a subset of the goods (which differs across people in a random way) and differ by their type, i.e. the proportion of regulated goods they consume. This proportion is denoted by $r$, while the proportion of regulated goods in the entire set of goods is now denoted by $\bar{r}$. Under reform, $\bar{r}$ falls to $\bar{r}^{\prime}=\lambda \bar{r}$, with $\lambda \in[0,1)$. Reform is assumed to affect people proportionally. That is, after the reform an agent who originally consumed a fraction $r$ of regulated goods now consumes a fraction $r^{\prime}=\lambda r$.

Given a reform scheme characterized by $\lambda$ and $\tau$, we can compute the fraction of winners from the reform in each group (nonregulated, deregulated, nonderegulated). One can show that for the nonregulated, there exists a critical $r^{*}$ such that an individual of type $r$ benefits from the reform iff $r \geq r^{*}$.

Table 2 gives an example, where $r$ is uniformly distributed in the population, and the tax rate is set to the lowest value such that all deregulated agents benefit from the reform, i.e. losers are compensated.

\footnotetext{
${ }^{14}$ See Appendix for analytical details.
} 


\begin{tabular}{llll}
\hline \hline$\lambda$ & $\tau(\%)$ & \multicolumn{2}{l}{ fraction of winners (\%) among } \\
& & nonregulated & non deregulated \\
\hline 0 & 7.6 & 60.8 & 85.0 \\
0.1 & 6.7 & 61.8 & 86.7 \\
0.2 & 5.8 & 63.0 & 88.4 \\
0.3 & 4.9 & 64.4 & 90.0 \\
0.4 & 4.1 & 65.4 & 91.7 \\
0.5 & 3.3 & 66.7 & 95.0 \\
0.6 & 2.6 & 67.3 & 95.0 \\
0.7 & 1.9 & 68.3 & 96.7 \\
0.8 & 1.3 & 67.5 & 96.7 \\
0.9 & 0.7 & 65.2 & 91.7 \\
\hline \hline
\end{tabular}

Table 2 - Support for reform by groups as a function of reform size under full loser compensation. See Appendix for derivations and parameter values.

In this example, reform is not Pareto-improving but has a wide support. The nonderegulated are more likely to benefit than the regulated, presumably because of the additional effect of the rise in their labor supply, which is constrained to be lower than their privately optimal level. The tax rate goes up with the size of the reform. This is not surprising since the number of people who would be compensated goes up. It is also true, however, that the impact of the reform goes up commensurately with its scope: consumers pay higher taxes as $\lambda$ falls but more goods have their price reduced. Furthermore, the broader the reform, the more a given deregulated group benefits from it, through deregulation in other sectors. This effect should dampen the rise in tax rates when reform becomes wider and suggests that broad reforms should have more support than narrow ones. In fact, this is only true in a limited sense: for each group support is hump-shaped in $\lambda$. The reform range that delivers the highest proportion of winners is $\lambda=0.7$, i.e. a deregulation of $30 \%$ of the regulated sector ${ }^{15}$.

\footnotetext{
${ }^{15}$ The tax rate divided by reform size, $\tau /(1-\lambda)$, is U-shaped in $\lambda$ and reaches its minimum at $\lambda=0.6$.
} 


\subsubsection{Example 2}

Goods a represented on a circle, with good $j=1$ being identified with good $j=0$. Agents are uniformly distributed over this circle, and they all consume a fraction $\rho$ of the goods. Hence, an agent located at $x$ consumes goods $[x, x+\rho \bmod 1]$. The distribution of preferences is independent of the allocation of producers to sectors. Hence the producers of good $j$, in terms of preferences, are uniformly allocated over the circle. The regulated goods are those such that $j \in[0, \bar{r}]$. We assume $1-\bar{r}>\rho>\bar{r}$.

Table 3 reports the outcome of the same exercise as in the preceding example. Total support for the reform is now lower, and broadening its scope unambiguously raises its support. If reform is too timid $\left(\bar{r}^{\prime} \geq 0.21\right)$, it cannot command a majority in the population, unless of course one gives up compensating all the deregulated agents.

\begin{tabular}{|c|c|c|c|c|}
\hline \multirow[t]{2}{*}{$\overline{\bar{r}^{\prime}}$} & \multirow[t]{2}{*}{$\tau(\%)$} & \multicolumn{2}{|c|}{ fraction of winners (\%) among } & \multirow[b]{2}{*}{ total } \\
\hline & & nonregulated & non deregulated & \\
\hline 0 & 9.6 & 46 & 45 & 62.2 \\
\hline 0.03 & 8.5 & 45.8 & 46 & 60.5 \\
\hline 0.06 & 7.4 & 45.7 & 45 & 58.7 \\
\hline 0.09 & 6.4 & 45.3 & 46 & 56.8 \\
\hline 0.12 & 5.4 & 44.8 & 45 & 54.7 \\
\hline 0.15 & 4.4 & 44.3 & 44 & 52.6 \\
\hline 0.18 & 3.5 & 43.5 & 43 & 50.2 \\
\hline 0.21 & 2.6 & 42.7 & 43 & 47.9 \\
\hline 0.24 & 1.7 & 41.9 & 43 & 45.7 \\
\hline 0.27 & 0.9 & 40.8 & 40 & 42.4 \\
\hline
\end{tabular}

$\overline{\text { Table } 3 \text { - Support for reform by groups as a function of }}$ reform size under full loser compensation. See Appendix for derivations and parameter values.

Unlike the preceding example, the impact of reform is far from uniform across preference groups. Some people do not consume any regulated good; others consume a range of regulated goods which is not affected by the reform. This generates a fairly large group who loses from taxation. Broadening reform scope shrinks the size of this group by making it less likely that somebody does not consume any deregulated good. 


\section{Conclusion}

I believe this paper has established some useful benchmark results regarding the viability of structural reforms under compensatory transfers and distortionary taxation. While these results can be overturned, especially under informational rents, they at least suggest that structural reforms cannot be undermined by their budgetary cost, provided these costs are correctly evaluated in welfare terms. Hence, why some reforms appear difficult to implement remains a productive avenue for future research. 


\section{Appendix}

\subsection{Proof of Lemma 1}

The first formula in claim $\mathrm{A}$ is straightforward from the definition of the aggregate price level.

Households such that $i>r$ now pay a proportional tax $\tau$. Their income is $l(1-\tau)$ and consequently their labor supply is

$$
l=l_{N}^{\prime}=p^{\prime-\frac{1}{\gamma-1}}(1-\tau)^{\frac{1}{\gamma-1}} .
$$

Furthermore, their utility is

$$
u_{N}^{\prime}=\left(1-\frac{1}{\gamma}\right)\left(\frac{1-\tau}{p^{\prime}}\right)^{\frac{\gamma}{\gamma-1}} .
$$

They benefit from the reform scheme iff $u_{N}^{\prime} \geq u_{N}$, or equivalently

$$
1-\tau \geq \frac{p^{\prime}}{p}
$$

which proves claim B for the nonregulated groups.

Households such that $r^{\prime}<i \leq r$ are now deregulated and face the same price vectors as those with $i>r$. By linearity of the indirect utility function, their labor supply is the same, $l_{N}^{\prime}=\left(p^{\prime}(1-\tau)\right)^{-\frac{1}{\gamma-1}}$. This, together with (41), proves claim A's second formula. Also, their disposable income is $R_{D}^{\prime}=$ $T+p^{\prime-\frac{1}{\gamma-1}}(1-\tau)^{\frac{\gamma}{\gamma-1}}$ and their utility is

$$
u_{D}^{\prime}=\frac{T}{p^{\prime}}+\left(1-\frac{1}{\gamma}\right) p^{-\frac{\gamma}{\gamma-1}}(1-\tau)^{\frac{\gamma}{\gamma-1}} .
$$

These people benefit from the reform provided $u_{D}^{\prime} \geq u_{R}$, i.e.

$$
T \geq p^{\prime-\frac{1}{\gamma-1}} \frac{\gamma-1}{\gamma}\left[\left(\frac{p^{\prime}}{p}\right)^{\frac{\gamma}{\gamma-1}} J-(1-\tau)^{\frac{\gamma}{\gamma-1}}\right] .
$$

This proves formula (10) in the text.

Finally, households such that $i \leq r^{\prime}$ have an income equal to $R_{R}^{\prime}=$ $\bar{l}^{\prime} p_{R}(1-\tau)$ and their labor supply is constrained to be equal to $\bar{l}^{\prime}$. Consequently, their utility is

$$
u_{R}^{\prime}=\frac{p_{R} \bar{l}^{\prime}(1-\tau)}{p^{\prime}}-\frac{\bar{l}^{\prime} \gamma}{\gamma}
$$


Again, the equilibrium rationed labor supply in the regulated sectors can be obtained from the equilibrium condition in any of the non regulated good:

$l_{N}^{\prime}=(1-r) c_{N}\left(p^{\prime-\frac{1}{\gamma-1}}(1-\tau)^{\frac{\gamma}{\gamma-1}}, p^{\prime}\right)+\Delta r c_{N}\left(p^{-\frac{1}{\gamma-1}}(1-\tau)^{\frac{\gamma}{\gamma-1}}+T, p^{\prime}\right)+r^{\prime} c_{N}\left(\bar{l}^{\prime} p_{R}(1-\tau), p^{\prime}\right)$,

or equivalently

$p^{\prime-\frac{1}{\gamma-1}}(1-\tau)^{\frac{1}{\gamma-1}}=(1-r) p^{\frac{\alpha}{1-\alpha}-\frac{1}{\gamma-1}}(1-\tau)^{\frac{\gamma}{\gamma-1}}+\Delta r\left[p^{\frac{\alpha}{1-\alpha}-\frac{1}{\gamma-1}}(1-\tau)^{\frac{\gamma}{\gamma-1}}+T p^{\frac{\alpha}{1-\alpha}}\right]+r^{\prime} \bar{l}^{\prime} p_{R}(1-\tau) p^{\frac{\alpha}{1-\alpha}}$

Using (2), this can be rearranged as

$$
r^{\prime} \bar{l}^{\prime} p_{R}(1-\tau)=p^{\prime-\frac{1}{\gamma-1}}(1-\tau)^{\frac{1}{\gamma-1}}\left[r^{\prime} p_{R}^{-\frac{\alpha}{1-\alpha}}+\tau\left(1-r^{\prime}\right)\right]-T \Delta r
$$

Total tax revenues are equal to $\tau\left[\left(1-r^{\prime}\right) l_{N}^{\prime}+r^{\prime} p_{R} \bar{l}^{\prime}\right]$, implying that the government budget constraint can be written as

$$
T \Delta r=\tau\left(1-r^{\prime}\right) p^{\prime-\frac{1}{\gamma-1}}(1-\tau)^{\frac{1}{\gamma-1}}+\tau r^{\prime} p_{R} \bar{l}^{\prime}
$$

We can eliminate $T$ between (47) and (48) to get an expression for $\bar{l}^{\prime}$ :

$$
\bar{l}^{\prime}=p_{R}^{-\frac{1}{1-\alpha}} p^{\prime-\frac{1}{\gamma-1}}(1-\tau)^{\frac{1}{\gamma-1}}
$$

This expression coincides with the third formula of claim A. Furthermore, the utility of the non deregulated groups can be rewritten as, using (8),(46), and (49)

$$
u_{R}^{\prime}=\frac{\gamma-1}{\gamma} p^{\prime-\frac{1}{\gamma-1}}(1-\tau)^{\frac{1}{\gamma-1}} J .
$$

This group gains from the reform provided $u_{R}^{\prime} \geq u_{R}$, or equivalently, from (50), (7), and (8):

$$
1-\tau \geq \frac{p^{\prime}}{p}
$$

which is clearly the same condition as (43), proving claim B for the nonderegulated groups. 
The equilibrium value of $\bar{l}^{\prime}$ can be substituted into (48) to reexpress the government's budget constraint:

$$
T=\frac{\tau(1-\tau)^{\frac{1}{\gamma-1}} p^{-\frac{1}{\gamma-1}-\frac{\alpha}{1-\alpha}}}{\Delta r} .
$$

This coincides with formula (11) in the text, which together with (45) proves claim C. Finally, claim D is straightforward from the preceding results.

\subsection{Proof of Proposition 1}

Substituting (51) into (44) we get that

$$
u_{D}^{\prime} \propto \gamma \tau(1-\tau)^{\frac{1}{\gamma-1}} p^{\prime-\frac{\alpha}{1-\alpha}}+\Delta r(\gamma-1)(1-\tau)^{\frac{\gamma}{\gamma-1}}
$$

where the proportionality factor is $>0$ and independent of $\tau$. Clearly then

$$
\frac{d}{d \tau} u_{D}^{\prime} \propto\left(p^{\prime-\frac{\alpha}{1-\alpha}}-\Delta r\right)-\frac{1}{\gamma-1} \frac{\tau}{1-\tau} p^{-\frac{\alpha}{1-\alpha}} .
$$

Since $p^{-\frac{\alpha}{1-\alpha}}-\Delta r=1-r+r^{\prime} p_{R}^{-\frac{\alpha}{1-\alpha}}>0$, claims (i) and (ii) follow immediately from this expression.

From (12) the condition $\tau_{\max } \geq 1-p^{\prime} / p$ is equivalent to

$$
-p p^{\prime-\frac{1}{1-\alpha}}+\gamma p^{\prime-\frac{\alpha}{1-\alpha}}-\Delta r(\gamma-1) \geq 0
$$

which from the definition of the price level can be rearranged as

$$
h\left(r^{\prime}\right)=-p p^{\prime}-\frac{1}{1-\alpha}+\gamma\left(r^{\prime} p_{R}^{-\frac{\alpha}{1-\alpha}}+1-r^{\prime}\right)-\Delta r(\gamma-1) \geq 0 .
$$

Let $X=r^{\prime} p_{R}^{-\frac{\alpha}{1-\alpha}}+1-r^{\prime}=p^{\prime-\frac{\alpha}{1-\alpha}}$. We note that:

$$
\frac{d p^{\prime}}{d r^{\prime}}=\frac{1-\alpha}{\alpha} X^{-\frac{1}{\alpha}}\left(1-p_{R}^{-\frac{\alpha}{1-\alpha}}\right)>0
$$

and

$$
\frac{d^{2} p^{\prime}}{d r^{\prime 2}}=\frac{1-\alpha}{\alpha^{2}} X^{-\frac{1}{\alpha}-1}\left(1-p_{R}{ }^{-\frac{\alpha}{1-\alpha}}\right)^{2}>0 .
$$


Next, observe that $h(r)>0$ and that

$$
\begin{aligned}
\frac{d^{2} h}{d r^{\prime 2}} & =\frac{\alpha-2}{(1-\alpha)^{2}} p p^{\prime \frac{2 \alpha-3}{1-\alpha}}\left(\frac{d p^{\prime}}{d r^{\prime}}\right)^{2}+\frac{1}{1-\alpha} p p^{\prime \frac{\alpha-2}{1-\alpha}} \frac{d^{2} p^{\prime}}{d r^{\prime 2}} \\
& \propto \frac{\alpha-2}{1-\alpha}\left(\frac{d p^{\prime}}{d r^{\prime}}\right)^{2} \frac{1}{p^{\prime}}+\frac{d^{2} p^{\prime}}{d r^{\prime 2}} \\
& =\left(1-p_{R}{ }^{-\frac{\alpha}{1-\alpha}}\right)^{2} X^{-\frac{1}{\alpha}-1} \frac{(1-\alpha)(\alpha-1)}{\alpha^{2}}<0
\end{aligned}
$$

Therefore $h$ is concave. Consequently, since $h(r)>0$, either $h(0) \geq 0$ and $h\left(r^{\prime}\right) \geq 0, \forall r^{\prime} \in[0, r]$, or $h(0)<0$, in which case $h(r)>0$ for $r<\tilde{r}$ and $\geq 0$ for $r \geq \tilde{r}$, where $\tilde{r}$ is the unique solution in $(0, r)$ to $h(\tilde{r})=0$. To complete the proof, we just need to check that the condition $h(0) \geq 0$ coincides with (13), which is straightforward.

QED

Remark: we have that

$$
\begin{aligned}
& \lim _{\gamma \rightarrow 1} \tau_{\max }=0 \\
& \lim _{\gamma \rightarrow 1} h(r)=0,
\end{aligned}
$$

and hence by continuity

$$
\lim _{\gamma \rightarrow 1} \tilde{r}=r
$$

QED

\subsection{Proof of Proposition 2}

A sufficient condition for the existence of viable reforms is that (45) hold for the maximum tax rate compatible with the nonderegulated groups participation constraint, i.e. $\tau=1-p^{\prime} / p$. Using (45) and (51) and rearranging, this is equivalent to

$$
p p^{\prime-\frac{1}{1-\alpha}}-p^{\prime-\frac{\alpha}{1-\alpha}} \geq \Delta r \frac{\gamma-1}{\gamma}(J-1)
$$

or equivalently

$$
h\left(r^{\prime}\right)=p p^{-\frac{1}{1-\alpha}}-\left(r^{\prime} p_{R}^{-\frac{\alpha}{1-\alpha}}+1-r^{\prime}\right)-\Delta r \frac{\gamma-1}{\gamma}(J-1) \geq 0
$$


Note that $h(r)=0$. Furthermore, from (52)

$$
\frac{d}{d r^{\prime}} h\left(r^{\prime}\right)=\frac{\gamma-1}{\gamma}(J-1)+\left(1-p_{R}^{-\frac{\alpha}{1-\alpha}}\right)\left(1-\frac{1}{\alpha} \frac{p}{p^{\prime}}\right) .
$$

As $r^{\prime}$ goes, up, so does $p^{\prime}$. Clearly, then, since $\left(1-p_{R}^{-\frac{\alpha}{1-\alpha}}\right) / \alpha>0$,

$$
\frac{d^{2}}{d r^{\prime 2}} h\left(r^{\prime}\right)>0
$$

Therefore, the $h$ function is convex. From (54) and (8) we get that $d h / d r^{\prime} \leq 0$ at $r^{\prime}=r$ iff

$$
\frac{1}{\alpha} p_{R}^{-\frac{\alpha}{1-\alpha}}-\frac{1}{\gamma} p_{R}^{-\frac{\gamma}{1-\alpha}} \leq \frac{1}{\alpha}-\frac{1}{\gamma}
$$

This holds with equality for $p_{R}=1$. Furthermore, the derivative of the LHS with respect to $p_{R}$ has the same sign as $p_{R}^{\frac{\alpha-\gamma}{1-\alpha}}-1<0$. Therefore, (55) always holds. Therefore, $h^{\prime}(r) \leq 0$, implying from convexity that $h^{\prime}\left(r^{\prime}\right)<0$ for all $r^{\prime}<r$. Therefore, since $h(r)=0, h\left(r^{\prime}\right)>0$ for all $r^{\prime}<r$. This proves claim (i).

To prove the two other claims, note that $u_{N}^{\prime}$ and $u_{R}^{\prime}$ are decreasing functions of $\tau$, while $u_{D}^{\prime}<u_{R}$ for $\tau=T=0$.

If $\tau_{\max } \geq 1-p^{\prime} / p$, then $u_{D}^{\prime}$ goes up with $\tau$ for $\tau \in\left[0,1-p^{\prime} / p\right]$. Since $u_{D}^{\prime}<u_{R}$ at $\tau=0$ and $u_{D}^{\prime}>u_{R}$ at $\tau=1-p^{\prime} / p$, as proved above, by continuity there exists $\tau_{c} \in\left(0,1-p^{\prime} / p\right)$ such that $u_{D}^{\prime}=u_{R}$ at $\tau=\tau_{C}$. Since $u_{D}^{\prime}$ is increasing in $\tau$ over $\left[0,1-p^{\prime} / p\right]$ and $u_{N}^{\prime}$ and $u_{R}^{\prime}$ are decreasing in $\tau$, it follows that the reform viability set is $\left[\tau_{c}, 1-p^{\prime} / p\right]$. This proves claim (ii).

If $\tau_{\max }<1-p^{\prime} / p, u_{D}^{\prime}$ falls with $\tau$ over $\left[\tau_{\max }, 1-p^{\prime} / p\right]$. Since $u_{D}^{\prime}>u_{R}$ at $\tau=1-p^{\prime} / p$, clearly $u_{D}^{\prime}>u_{R}$ for all $\tau \in\left[\tau_{\max }, 1-p^{\prime} / p\right]$. By continuity again, there exists $\tau_{c} \in\left(0, \tau_{\max }\right)$ such that $u_{D}^{\prime}=u_{R}$ at $\tau=\tau_{c}$. Since $u_{D}^{\prime}$ is hump-shaped and reaches its maximum at $\tau_{\max }$, clearly $u_{D}^{\prime} \geq u_{R}$ for $\tau \in$ $\left[\tau_{c}, 1-p^{\prime} / p\right]$. Since $u_{D}^{\prime}<u_{R}$ for lower values of $\tau$ and $u_{N}^{\prime}<u_{N}$ for greater values of $\tau$, this again coincides with the reform viability set. The claim about Pareto dominance follows straightforwardly from the observation that $u_{D}^{\prime}, u_{R}^{\prime}$ and $u_{N}^{\prime}$ all fall with $\tau$ over $\left(\tau_{\max }, 1-p^{\prime} / p\right]$. This completes the proof of claim (ii) and therefore of Proposition 2. 


\subsection{Proof of Lemma 2}

It is straightforward to see that (41) and (42) still hold. Therefore, the participation constraint of the nonregulated groups, (43), still holds, and this proves claim B,as well as the second formula of claim A, while the first one is obvious. Also, their demand for nonregulated goods is $c_{N}\left(p^{\prime-\frac{1}{\gamma-1}}(1-\right.$ $\left.\tau)^{\frac{\gamma}{\gamma-1}}, p^{\prime}\right)$. As for regulated groups, their income is $T+p_{R}^{\prime} \bar{l}^{\prime}(1-\tau)$, and their demand for nonregulated goods is $c_{N}\left(\bar{l}^{\prime} p_{R}^{\prime}(1-\tau), p^{\prime}\right)$. These observations allow us to rewrite the equilibrium condition for nonregulated goods:

$$
l_{N}^{\prime}=(1-r) c_{N}\left(p^{\prime-\frac{1}{\gamma-1}}(1-\tau)^{\frac{\gamma}{\gamma-1}}, p^{\prime}\right)+r c_{N}\left(\bar{l}^{\prime} p_{R}^{\prime}(1-\tau)+T, p^{\prime}\right) .
$$

The government's budget constraint is

$$
r T=\tau\left[(1-r) p^{-\frac{1}{\gamma-1}}(1-\tau)^{\frac{\gamma}{\gamma-1}}+r \bar{l}^{\prime} p_{R}^{\prime}(1-\tau)\right] .
$$

Eliminating $T$ between these two equations allows us again to compute the new value of employment in regulated sectors:

$$
\bar{l}^{\prime}=p_{R}^{\prime-\frac{1}{1-\alpha}} p^{\prime-\frac{1}{\gamma-1}}(1-\tau)^{\frac{1}{\gamma-1}}
$$

which proves the third expression in claim B.

Substituting into (56) yields

$$
T=\frac{\tau}{r}(1-\tau)^{\frac{1}{\gamma-1}} p^{\prime-\frac{1}{\gamma-1}-\frac{\alpha}{1-\alpha}} .
$$

This in turn allows us to compute the regulated group's utility level:

$$
u_{R}^{\prime}=\frac{\tau}{r}(1-\tau)^{\frac{1}{\gamma-1}} p^{\prime-\frac{\gamma}{\gamma-1}-\frac{\alpha}{1-\alpha}}+p^{\prime-\frac{\gamma}{\gamma-1}}(1-\tau)^{\frac{\gamma}{\gamma-1}} \frac{\gamma-1}{\gamma} J^{\prime},
$$

where

$$
J^{\prime}=\frac{\gamma p_{R}^{\prime-\frac{\alpha}{1-\alpha}}-p_{R}^{\prime-\frac{\gamma}{1-\alpha}}}{\gamma-1} .
$$

Comparing (58) with (7), using the expressions for $J$ and $J^{\prime}$, delivers the expression in claim C. Finally, claim D derives from preceding statements. 


\subsection{Proof of Proposition 3}

We proceed as in the proof of Proposition 2. That is, we show that (??) holds with strict inequality if one picks $\tau=1-p^{\prime} / p$. Substituting into (??) and simplifying, we have to prove the following inequality:

$$
p p^{\prime-\frac{1}{1-\alpha}}-p^{\prime-\frac{\alpha}{1-\alpha}}>r \frac{\gamma-1}{\gamma}\left(J-J^{\prime}\right) .
$$

We note that both sides coincide at $p_{R}^{\prime}=p_{R}$. We next show that $\varphi\left(p_{R}^{\prime}, p_{R}\right) \equiv \frac{\partial}{\partial p_{R}^{\prime}}\left[p p^{-\frac{1}{1-\alpha}}-p^{\prime-\frac{\alpha}{1-\alpha}}-r \frac{\gamma-1}{\gamma}\left(J-J^{\prime}\right)\right]<0$ for $1 \leq p_{R}^{\prime} \leq p_{R}$.

To see this, note that

$$
\frac{\partial p}{\partial p_{R}}=r p_{R}^{-\frac{1}{1-\alpha}} p^{\frac{1}{1-\alpha}}
$$

and that

$$
\frac{\partial J}{\partial p_{R}}=\frac{\gamma}{(\gamma-1)(1-\alpha)}\left[p_{R}^{-\frac{\gamma}{1-\alpha}-1}-p_{R}^{-\frac{1}{1-\alpha}}\right]
$$

It then follows from straightforward calculations that

$$
\varphi \propto \alpha-1-p / p^{\prime}+p_{R}^{\prime \frac{\alpha-\gamma}{1-\alpha}} .
$$

Since $p^{\prime} \leq p$ and $p_{R}^{\prime} \geq 1$, this expression is clearly smaller than $\alpha-1-$ $1+1=\alpha-1<0$. Since $\varphi<0$ and (60) holds with equality in the limit case where $p_{R}^{\prime}=p_{R}$, clearly (60) holds for any $p_{R}^{\prime} \in\left[1, p_{R}\right)$.

The rest of the proof is the same as for Proposition 2.

QED.

\subsection{Proof of Proposition 4}

First, note that claim (iii) follows straightforwardly from the definition of the income of group $i$.

Next, let us prove claims (i) and (ii). Let $\mathbf{S}$ be the matrix whose generic element is

$$
s_{i j}=\frac{1}{u} \frac{\partial^{2} u}{\partial c_{i} \partial c_{j}}-\frac{1}{u^{2}} \frac{\partial u}{\partial c_{i}} \frac{\partial u}{\partial c_{j}} .
$$


Then $\mathbf{S}$ is the sum of two matrices, one with generic element $\frac{1}{u} \frac{\partial^{2} u}{\partial c_{i} \partial c_{j}}$, which is negative semi-definite, the other with generic element $-\frac{1}{u^{2}} \frac{\partial u}{\partial c_{i}} \frac{\partial u}{\partial c_{j}}$ which is negative definite. Consequently $\mathbf{S}$ is negative definite and therefore invertible. Furthermore, the FOC is $(\boldsymbol{\nabla} u)^{T}=\lambda \mathbf{p}$ (where $\lambda$ here is a scalar denoting the consumer's problem's Lagrange multiplier). Since by Euler's theorem $\left\langle\mathbf{c},(\boldsymbol{\nabla} u)^{T}\right\rangle=u$, and $R=\langle\mathbf{p}, \mathbf{c}\rangle, \lambda=u / R$. Hence $\frac{1}{u}(\boldsymbol{\nabla} u)^{T}=\frac{\mathbf{p}}{R}$. Since $\mathbf{S}=\boldsymbol{\nabla} \frac{1}{u}(\boldsymbol{\nabla} u)^{T}$, we have that the derivative of $\mathbf{c}$ with respect to $\mathbf{p}$ is $R \boldsymbol{\nabla} \boldsymbol{\psi}=$ $\mathbf{S}^{-1} / R$. Therefore

$$
\boldsymbol{\nabla} \boldsymbol{\psi}=\frac{1}{R^{2}} \mathbf{S}^{-1}
$$

implying that $\boldsymbol{\nabla} \boldsymbol{\psi}$ is invertible. By definition, our price normalization is such that $u=R$. Hence $\lambda=1$ and $(\boldsymbol{\nabla} u)^{T}=\mathbf{p}$. Also $\langle\mathbf{p}, \mathbf{c}\rangle=R=u$, implying $d u=\langle\mathbf{p}, \mathbf{d} \mathbf{c}\rangle+\langle\mathbf{d} \mathbf{p}, \mathbf{c}\rangle$. But, by definition of the gradient, $\left\langle\mathbf{d} \mathbf{c},(\boldsymbol{\nabla} u)^{T}\right\rangle=d u$. Therefore

$$
\langle\mathbf{d p}, \mathbf{c}\rangle=0
$$

Equivalently

$$
\langle\mathbf{s}, \mathbf{d p} \div \mathbf{p}\rangle=0
$$

From (26), and the obvious remark that $\langle\mathbf{1}, x \bullet \mathbf{y}\rangle=\langle x, \mathbf{y}\rangle$, we have that

$$
d W=d Y-\left\langle v^{\prime}(\mathbf{l}), \mathbf{d} \mathbf{l}\right\rangle
$$

We have that

$$
d Y=\langle\mathbf{1}, \mathbf{d R}\rangle
$$

and from (29)

$$
\mathbf{d R}=\mathbf{p} \bullet \mathbf{d l}+\mathbf{l} \bullet \mathbf{d p}-Y \mathbf{s} \bullet \mathbf{d} \tau+\mathbf{d T},
$$

implying, by virtue of the government's budget constraint (21), that

$$
\begin{aligned}
d Y & =\langle\mathbf{1}, \mathbf{p} \bullet \mathbf{d} \mathbf{l}+\mathbf{l} \bullet \mathbf{d} \mathbf{p}\rangle \\
& =\langle\mathbf{p}, \mathbf{d} \mathbf{l}\rangle+\langle\mathbf{l}, \mathbf{d} \mathbf{p}\rangle \\
& =\langle\mathbf{p}, \mathbf{d l} \mathbf{l}\rangle \\
& =Y\langle\mathbf{s}, \mathbf{d} \mathbf{l} \div \mathbf{l}\rangle
\end{aligned}
$$


Where, since $\mathbf{l}=\mathbf{c}$ at the aggregate level, (62), has been used. This proves (ii). Similarly,

$$
\begin{aligned}
d W & =\left\langle\mathbf{p}-v^{\prime}(\mathbf{l}), \mathbf{d} \mathbf{l}\right\rangle \\
& =\langle\mathbf{p} \bullet \omega, \mathbf{d} \mathbf{l}\rangle \\
& =Y\langle\mathbf{s} \bullet \omega, \mathbf{d} \mathbf{l} \div \mathbf{l}\rangle
\end{aligned}
$$

This proves point (i).

Now consider a PSR such that (27) holds. Observe that an SRST with the same price changes for regulated goods results in the same equilibrium for prices and labor supply, and therefore the same $d Y$. For any $i$, the corresponding change in welfare is

$$
\begin{aligned}
d U_{i} & =d R_{i}-v^{\prime}\left(l_{i}\right) d l_{i} \\
& =s_{i} Y\left(\frac{d p_{i}}{p_{i}}+\frac{d l_{i}}{l_{i}}\right)+d T_{i}-p_{i} d l_{i} \\
& =s_{i} Y\left(\frac{d p_{i}}{p_{i}}+\omega_{i} \frac{d l_{i}}{l_{i}}\right)+d T_{i} .
\end{aligned}
$$

(This formula also holds for $i \in N$, in which case $\omega_{i}=0$.

Let $x=\langle\mathbf{s} \bullet \boldsymbol{\omega}, \mathbf{d} \mathbf{l} \div \mathbf{l}\rangle Y / q>0$. Consider the transfer scheme

$$
\mathbf{d T}=-Y(\mathbf{s} \bullet \mathbf{d p} \div \mathbf{p}+\mathbf{s} \bullet \boldsymbol{\omega} \bullet \mathbf{d l} \div \mathbf{l})+x \mathbf{1}
$$

Clearly, $d U_{i}=x>0$. Furthermore

$$
\begin{aligned}
\langle\mathbf{1}, \mathbf{d T}\rangle & =-Y\langle\mathbf{s}, \mathbf{d} \mathbf{p} \div \mathbf{p}\rangle-Y\langle\mathbf{s} \bullet \boldsymbol{\omega}, \mathbf{d} \mathbf{l} \div \mathbf{l}\rangle+q x \\
& =0
\end{aligned}
$$

by (63). The transfer scheme satisfies the budget constraint (22). Thus the proposed SRST implements the same productive allocation as the PSR in a Pareto-improving way. This proves point (iv). QED.

\subsection{Proof of Proposition 5}

Assume an N-neutral reform such that (27) holds exists. Let us construct a Pareto-improving FSR. 
First we assume that $\mathbf{d} \boldsymbol{\tau}_{N}$ and $\mathbf{d} \mathbf{p}_{R}$ are the same, implying that the equilibrium values of $\mathbf{d p}$ and $\mathbf{d l}$ are unchanged.

Second, we assume $\mathbf{d} \mathbf{T}_{N}=0$. Hence the alternative reform is also Nneutral, and the feasibility constraint $d T_{i} \geq 0$ holds for $i \in N$.

For $i \in R$, the change in welfare is

$$
d U_{i}=s_{i} Y\left(\frac{d p_{i}}{p_{i}}+\omega_{i} \frac{d l_{i}}{l_{i}}\right)+d \tilde{T}_{i}
$$

where $d \tilde{T}_{i}$ can be chosen independently of the feasibility constraint since it is always possible to then pick, for example $d \tau_{i}=-d \tilde{T}_{i} /\left(s_{i} Y\right)$ and $d T_{i}=0$.

Let $x=\langle\mathbf{s} \bullet \boldsymbol{\omega}, \mathbf{d} \mathbf{l} \div \mathbf{l}\rangle Y / r>0$. Let us pick

$$
\mathbf{d} \tilde{\mathbf{T}}_{R}=-Y\left(\mathbf{s}_{R} \bullet \mathbf{d} \mathbf{p}_{R} \div \mathbf{p}_{R}+\mathbf{s}_{R} \bullet \boldsymbol{\omega}_{R} \bullet \mathbf{d} \mathbf{l}_{R} \div \mathbf{l}_{R}\right)+x \mathbf{1}_{R}
$$

Clearly, $d U_{i}=x>0$ for all $i \in R$. Furthermore,

$$
\begin{aligned}
\langle\mathbf{s}, \mathbf{d} \boldsymbol{\tau}\rangle Y-\langle\mathbf{1}, \mathbf{d} \mathbf{T}\rangle & =\left\langle\mathbf{s}_{N}, \mathbf{d} \boldsymbol{\tau}_{N}\right\rangle Y-\left\langle\mathbf{1}, \mathbf{d} \tilde{\mathbf{T}}_{R}\right\rangle \\
& =\left\langle\mathbf{s}_{N}, \mathbf{d} \mathbf{p}_{N} \div p_{N}\right\rangle Y+\left\langle\mathbf{s}_{R}, \mathbf{d p}_{R} \div p_{R}\right\rangle Y+\left\langle\mathbf{s}_{R} \bullet \boldsymbol{\omega}_{R}, \mathbf{d l}_{R} \div \mathbf{l}_{R}\right\rangle Y-r x \\
& =\langle\mathbf{s}, \mathbf{d p} \div p\rangle Y+\langle\mathbf{s} \bullet \boldsymbol{\omega}, \mathbf{d l} \div \mathbf{l}\rangle Y-r x \\
& =0,
\end{aligned}
$$

by (63) and the fact that $\omega_{i}=0$ for $i \in N$. Hence, the proposed transfer scheme satisfies the government's budget constraint.

Our constructed FSR clearly matches all requirements.

QED.

\subsection{Proof of Proposition 6}

Let us first write the equilibrium conditions in differential form. For any consumer with income $R$,

$$
\mathbf{d c}=R \nabla \boldsymbol{\psi} \mathbf{d p}+\boldsymbol{\psi} d R
$$


Therefore

$$
\mathbf{d} \mathbf{l} \div \mathbf{l}=\mathbf{1} \frac{d Y}{Y}+\mathbf{M}(\mathbf{d p} \div \mathbf{p})
$$

with

$$
m_{i j}=\frac{p_{j}}{\psi_{i}}[\boldsymbol{\nabla} \boldsymbol{\psi}]_{i j}
$$

Clearly, $\mathbf{M}$ is invertible since $\nabla \psi$ is.

Let

$$
\eta_{i}=p_{i} \frac{\lambda^{\prime}\left(p_{i}\right)}{\lambda\left(p_{i}\right)}
$$

be the elasticity of labor supply for group $i$. The labor supply conditions for the nonregulated can be written as

$$
\mathbf{d} \mathbf{l}_{N} \div \mathbf{l}_{N}=\boldsymbol{\eta} \bullet\left(\mathbf{d} \mathbf{p}_{N} \div \mathbf{p}_{N}-\mathbf{d} \boldsymbol{\tau}_{N}\right)
$$

Finally, the price normalization condition boils down to (63).

For an N-neutral reform, $\mathbf{d} \tau_{N}$ becomes endogenous, and the set of equations that characterize the equilibrium is

$$
\begin{aligned}
{\left[\mathbf{1} \frac{d Y}{Y}+\mathbf{M}(\mathbf{d} \mathbf{p} \div \mathbf{p})\right]_{N} } & =\mathbf{0}_{N} \\
\langle\mathbf{s}, \mathbf{d} \mathbf{p} \div \mathbf{p}\rangle & =0
\end{aligned}
$$

that is, $n+1$ equations in $n+1$ unknowns: $\mathbf{d p}_{N}$ and $d Y$, as $\mathbf{d p}_{R}$ is exogenous. The allocation of labor can then be computed residually from (64) and it will obviously satisfy $\mathbf{d l}_{N}=0$. The tax rates imposed upon the nonregulated are computed residually as $\mathbf{d} \boldsymbol{\tau}_{N}=\mathbf{d} \mathbf{p}_{N} \div \mathbf{p}_{N}$. Generically, then, one can always construct an N-neutral fiscal scheme for any change in $\mathbf{d p}_{N}$. This does not tell us, however, whether it matches (27).

To show that such reforms exist, consider the reverse problem. Pick any vector of employment growth in regulated sectors, $\mathrm{dl}_{R} \div \mathbf{l}_{R}$. Obviously, it is always possible to choose it so that (27) holds. This will in particular be the case if $\mathbf{d l}_{R} \geq 0$, with at least one strict inequality.

Next, choose $d Y / Y=\left\langle\mathbf{s}_{R}, \mathbf{d l}_{R} \div \mathbf{l}_{R}\right\rangle$. We are going to check that this choice is indeed consistent with equilibrium. For this, let $v_{i}=-d Y / Y$ if 
$i \in N$ and $v_{i}=d l_{i} / l_{i}-d Y / Y$ for $i \in R$. Clearly, from (64), ,one must have

$$
\mathbf{d p} \div \mathbf{p}=\mathbf{M}^{-1} \mathbf{v}
$$

Since $\mathbf{M}$ is invertible, we can always choose this vector of price changes. Its restriction to $R,[\mathbf{d} \mathbf{p} \div \mathbf{p}]_{R}$, delivers the set of changes in regulated prices necessary to deliver the desired level of employment growth under an $\mathrm{N}$ neutral reform.

By construction, the candidate equilibrium matches (65). To complete the proof, we just have to check that it satisfies (63).

Differentiating (17) we find that for any price vector

$$
\nabla \psi(\mathbf{p}) \mathbf{p}+\psi(\mathbf{p}) \equiv \mathbf{0}
$$

We have that

$$
\begin{aligned}
\langle\mathbf{s}, \mathbf{M}(\mathbf{d} \mathbf{p} \div \mathbf{p})\rangle & =\langle\mathbf{p}, \boldsymbol{\nabla} \boldsymbol{\psi}(\mathbf{p}) \mathbf{d} \mathbf{p}\rangle \quad \text { (by definition of } \mathbf{M}) \\
& =\langle\boldsymbol{\nabla} \boldsymbol{\psi}(\mathbf{p}) \mathbf{p}, \mathbf{d} \mathbf{p}\rangle \quad(\text { since } \boldsymbol{\nabla} \boldsymbol{\psi}(\mathbf{p}) \text { is symmetrical) } \\
& =-\langle\boldsymbol{\psi}(\mathbf{p}), \mathbf{d} \mathbf{p}\rangle \quad(\text { by }(67)) \\
& =-\langle\mathbf{s}, \mathbf{d} \mathbf{p} \div \mathbf{p}\rangle .
\end{aligned}
$$

Finally by construction $\langle\mathbf{s}, \mathbf{M}(\mathbf{d} \mathbf{p} \div \mathbf{p})\rangle=\langle\mathbf{s}, \mathbf{v}\rangle=-d Y / Y+\left\langle\mathbf{s}_{R}, \mathbf{d l}_{R} \div \mathbf{l}_{R}\right\rangle=$ 0 . Therefore, from the preceding derivation, (63) holds.

\subsection{Proof of Proposition 7}

We prove a series of Lemmas, which provide bounds for different properties of a reform, and together imply Proposition 7 .

LEMMA A1 - If

$$
\eta / \sigma<\frac{1}{2(n-1)}
$$

then for any r-vector $\mathbf{d x}$ there exists an N-reform such that $\mathbf{d} \mathbf{p}_{R} \div \mathbf{p}_{R}=-\mathbf{d x}$.

Proof - Let

$$
\mathbf{M}=\left(\begin{array}{ll}
\mathbf{M}^{N N} & \mathbf{M}^{N R} \\
\mathbf{M}^{R N} & \mathbf{M}^{R R}
\end{array}\right)
$$


Let

$$
\mathbf{z}=\left(\begin{array}{c}
\mathbf{d}_{\mathbf{p}_{N}} \div \mathbf{p}_{N} \\
d Y / Y
\end{array}\right)
$$

and let

$$
\mathbf{Q}=\left(\begin{array}{cc}
\mathbf{M}^{N N} & \mathbf{1} \\
\mathbf{s}_{N}^{T} & 0
\end{array}\right)
$$

The system (65-66) can be rewritten as

$$
\mathbf{Q z}=\left(\begin{array}{c}
\mathbf{M}^{N R} \mathbf{d x} \\
\left\langle\mathbf{s}_{R}, \mathbf{d x}\right\rangle
\end{array}\right)
$$

To show existence of an N-reform, we show that $\mathbf{Q}$ is invertible. First, since $\mathbf{M}$ differs from a negative definite matrix by a change of variables, $\operatorname{det} \mathbf{M}^{N N} \neq 0$. Second, let $\mathbf{v}=\mathbf{M}^{N N-1} \mathbf{1}$. Let $\xi=\max _{i \in N}\left|v_{i}\right|$. Since $\sum_{j=1}^{n} m_{i j} v_{j}=$ 1 , clearly $1 \geq(\sigma-(n-1) \eta) \xi$. From $(68), \sigma-(n-1) \eta>0$. Therefore $\xi \leq \frac{1}{\sigma-(n-1) \eta}$. For all $i, 1 \leq m_{i i} v_{i}+(n-1) \eta \xi \leq m_{i i} v_{i}+\frac{(n-1) \eta}{\sigma-(n-1) \eta}$. By $(68)$ again, we have that $\frac{(n-1) \eta}{\sigma-(n-1) \eta}<1$. Therefore, since $m_{i i}<0, v_{i}<0$. Consequently $\left\langle\mathbf{s}_{N}, \mathbf{v}\right\rangle<0$. One can then check that the inverse of $\mathbf{Q}$ is

$$
\mathbf{Q}^{-1}=\left(\begin{array}{cc}
\mathbf{M}^{N N-1}-\mathbf{v s}_{N}^{T} \mathbf{M}^{N N-1} /\left\langle\mathbf{s}_{N}, \mathbf{v}\right\rangle & \mathbf{v} /\left\langle\mathbf{s}_{N}, \mathbf{v}\right\rangle \\
\mathbf{s}_{N}^{T} \mathbf{M}^{N N-1} /\left\langle\mathbf{s}_{N}, \mathbf{v}\right\rangle & -1 /\left\langle\mathbf{s}_{N}, \mathbf{v}\right\rangle
\end{array}\right)
$$

QED

Since (31) implies (68), point (i) of Proposition 7 follows.

Next, let

$$
\mu=\left\langle\mathbf{s}_{R}, \boldsymbol{\sigma}_{R} \bullet \mathbf{d x}\right\rangle / s_{R}>0
$$

LEMMA A2 - If

$$
\eta<\frac{1}{q-1} \min \left(\frac{\mu}{x_{m}}, \sigma \frac{1-s_{R}}{1+s_{R}}\right),
$$

then any N-neutral reform such that $\mathbf{d p}_{R} \div \mathbf{p}_{R}=-\mathbf{d x}$ satisfies $d Y=0$.

Proof - Let

$$
K=\max _{i}\left|\frac{d p_{i}}{p_{i}}\right|>0
$$


From (64) and (28), and the fact that $\mathbf{d l}_{N}=\mathbf{0}$ by construction,

$$
\begin{aligned}
d Y / Y & =\frac{1}{1-s_{R}}\left\langle\mathbf{s}_{R},(\mathbf{M}(\mathbf{d} \mathbf{p} \div \mathbf{p}))_{R}\right\rangle \\
& \geq \frac{s_{R}}{1-s_{R}}(\mu-K \eta(q-1)) .
\end{aligned}
$$

For $i \in N$, we have that

$$
\begin{aligned}
-m_{i i} \frac{d p_{i}}{p_{i}} & =\frac{d Y}{Y}+\sum_{j \neq i} m_{i j} \frac{d p_{j}}{p_{j}} \\
& \geq \frac{s_{R}}{1-s_{R}}(\mu-K \eta(q-1))-K \eta(q-1) \\
& =\frac{1}{1-s_{R}}\left(s_{R} \mu-K \eta(q-1)\right) .
\end{aligned}
$$

Assume $K$ is reached for $i \in N$ and $d p_{i} / p_{i}<0$. Then for this $i, K=$ $-d p_{i} / p_{i}$ and the preceding inequality reads $\left(-m_{i i}\right) K \leq \frac{1}{1-s_{R}}\left(-s_{R} \mu+K \eta(q-\right.$ $1)$ ), implying $s_{R} \mu \leq K\left(\eta(q-1)-\sigma\left(1-s_{R}\right)\right)$. From (69), the RHS is negative. Since $\mu>0$, we then have a contradiction, so this case can be ruled out.

Assume next that $K$ is reached for $i \in R$, implying $d p_{i} / p_{i}<0$ for this $i$. Then by definition $K=x_{m}$ and from (71),

$$
d Y / Y \geq \frac{s_{R}}{1-s_{R}}\left(\mu-x_{m} \eta(q-1)\right),
$$

which is $>0$ from $(69)$.

Now assume that $K$ is reached for $i \in N$, so that for this $i d p_{i} / p_{i}>0$. From (70), we have that

$$
d Y / Y \leq \frac{s_{R}}{1-s_{R}}(\mu+K \eta(q-1))
$$

Together with (72), this implies that, for $i \in N$,

$$
\sigma_{i} \frac{d p_{i}}{p_{i}} \leq \frac{s_{R} \mu+K \eta(q-1)}{1-s_{R}} .
$$

Therefore, for $i \in N, \frac{d p_{i}}{p_{i}} \leq \frac{s_{R} \mu+K \eta(q-1)}{\sigma_{i}\left(1-s_{R}\right)} \leq \frac{s_{R} \mu+K \eta(q-1)}{\sigma\left(1-s_{R}\right)}$. Since $d p_{i} / p_{i}=K$ for some $i \in N$, it follows that

$$
K \leq \frac{s_{R} \mu}{\sigma\left(1-s_{R}\right)-\eta(q-1)}
$$


Substituting into (71) and rearranging, we get

$$
\frac{d Y}{Y} \geq \frac{s_{R} \mu}{1-s_{R}} \frac{\sigma\left(1-s_{R}\right)-\left(1+s_{R}\right) \eta(q-1)}{\sigma\left(1-s_{R}\right)-\eta(q-1)} .
$$

This is again $>0$ from (69).

QED.

Note that since $\mu=\sigma_{R} \bar{x}_{Y}$, condition (69) can be rewritten as

$$
\eta<\frac{1}{q-1} \min \left(\frac{\bar{x}_{Y}}{x_{m}} \sigma_{R}, \sigma \frac{1-s_{R}}{1+s_{R}}\right) .
$$

LEMMA A3 - If

$$
\eta<\frac{1}{q-1} \min \left(\frac{s_{R} \mu}{x_{m}}, \sigma \frac{1-s_{R}}{2}\right),
$$

then any N-neutral reform such that $\mathbf{d} \mathbf{p}_{R} \div \mathbf{p}_{R}=-\mathbf{d x}$ is such that $\mathbf{d l}_{R}>0$.

Proof - Start again with the case where $K$ is reached for $i \in R$. Using (64) and (73) we have that for $i \in R$

$$
\begin{aligned}
\frac{d l_{i}}{l_{i}} & \geq-\sigma_{i} \frac{d p_{i}}{p_{i}}+\frac{d Y}{Y}-\eta(q-1) K \\
& \geq \sigma_{i} d x_{i}+\frac{s_{R} \mu-x_{m} \eta(q-1)}{1-s_{R}} .
\end{aligned}
$$

Since $\sigma_{i}>0$ and $d x_{i} \geq 0$, it follows from (77) that the RHS is $>0$.

Assume now that $K$ is reached for $i \in N$. Using (64) together with (75) we get that for $i \in R$,

$$
\begin{aligned}
\frac{d l_{i}}{l_{i}} & \geq-\sigma_{i} \frac{d p_{i}}{p_{i}}-\eta(q-1) K+\frac{d Y}{Y} \\
& \geq \sigma_{i} d x_{i}+\frac{s_{R} \mu}{\sigma\left(1-s_{R}\right)-\eta(q-1)}\left(\sigma-\frac{2 \eta(q-1)}{1-s_{R}}\right) .
\end{aligned}
$$

Again this is $>0$ from (77).

QED. 
Note that since $\mu=\sigma_{R} \bar{x}_{Y}$, condition (77) is equivalent to (31), which proves point (ii) in Proposition 7.

Finally the following Lemma derives a weaker condition than (77) under which $d W>0$, in which case we know that the N-reform can be implemented in Pareto-improving way.

Let

$$
v=\left\langle\mathbf{s}_{R} \bullet \boldsymbol{\omega}_{R}, \boldsymbol{\sigma}_{R} \bullet \mathbf{d x}\right\rangle /\left\langle\mathbf{s}_{R}, \boldsymbol{\omega}\right\rangle \geq 0 .
$$

LEMMA A4 - If

$$
\eta<\frac{1}{q-1} \min \left(\frac{s_{R} \mu+\left(1-s_{R}\right) v}{x_{m}}, \sigma\left(1-s_{R}\right) \frac{s_{R} \mu+\left(1-s_{R}\right) v}{2 s_{R} \mu+\left(1-s_{R}\right) v}\right),
$$

then any N-neutral reform such that $\mathbf{d p}_{R} \div \mathbf{p}_{R}=-\mathbf{d x}$ is such that (27) holds, i.e. $d W>0$.

Proof - Assume $K$ is reached for $i \in R$. Then (78) holds. Furthermore, we know that $d W>0$ iff $\langle\mathbf{s} \bullet \boldsymbol{\omega}, \mathbf{d l} \div \mathbf{l}\rangle>0$. Multiplying both sides of (78) by $s_{i} \omega_{i}$ and summing over $i \in R$, we get that

$$
\langle\mathbf{s} \bullet \boldsymbol{\omega}, \mathbf{d l} \div \mathbf{l}\rangle \geq\left\langle\mathbf{s}_{R}, \boldsymbol{\omega}\right\rangle v+\left\langle\mathbf{s}_{R}, \boldsymbol{\omega}\right\rangle \frac{s_{R} \mu-x_{m} \eta(q-1)}{1-s_{R}} .
$$

From (80) the RHS is clearly $>0$.

Assume now $K$ is reached for $i \in N$. Then (79) holds and performing the same steps on (79) as on (78) yields

$$
\langle\mathbf{s} \bullet \boldsymbol{\omega}, \mathbf{d} \mathbf{l} \div \mathbf{l}\rangle \geq\left\langle\mathbf{s}_{R}, \boldsymbol{\omega}\right\rangle v+\left\langle\mathbf{s}_{R}, \boldsymbol{\omega}\right\rangle \frac{s_{R} \mu}{\sigma\left(1-s_{R}\right)-\eta(q-1)}\left(\sigma-\frac{2 \eta(q-1)}{1-s_{R}}\right)
$$

Since $v+\frac{s_{R} \mu}{\sigma\left(1-s_{R}\right)-\eta(q-1)}\left(\sigma-\frac{2 \eta(q-1)}{1-s_{R}}\right) \propto v\left(\sigma\left(1-s_{R}\right)-\eta(q-1)\right)+s_{R} \mu \sigma-$ $\frac{2 \eta(q-1)}{1-s_{R}} s_{R} \mu \propto \sigma\left(1-s_{R}\right)\left[v\left(1-s_{R}\right)+\mu s_{R}\right]-\eta(q-1)\left[v\left(1-s_{R}\right)+2 \mu s_{R}\right]$, the RHS is clearly $>0$ by (80).

QED. 


\subsection{Proof of Lemma 5}

The demand curves now are given by $c\left(R, 1, p_{k}\right)$. The real wage in nonregulated sectors is just $p_{N}$, so that

$$
l_{N}=p_{N}^{\frac{1}{\gamma-1}}
$$

From this it is straightforward to derive the equilibrium utility of the nonregulated:

$$
u_{N}=p_{N}^{\frac{\gamma}{\gamma-1}} \frac{\gamma-1}{\gamma}
$$

As for the regulated groups, their income is $p_{R} \bar{l}$. Their constrained employment level $\bar{l}$ can again be computed from the equilibrium condition in the nonregulated sector, $l_{N}=(1-r) c\left(p_{N}^{\frac{\gamma}{\gamma-1}}, 1, p_{N}\right)+r c\left(p_{R} \bar{l}, 1, p_{N}\right)$, yielding

$$
\bar{l}=p_{N}^{\frac{1}{\gamma-1}+\frac{1}{1-\alpha}} p_{R}^{-\frac{1}{1-\alpha}} .
$$

Therefore, the regulated groups' utility is equal to

$$
u_{R}=J u_{N}
$$

with

$$
J=\frac{\gamma\left(p_{R} / p_{N}\right)^{-\frac{\alpha}{1-\alpha}}-\left(p_{R} / p_{N}\right)^{-\frac{\gamma}{1-\alpha}}}{\gamma-1} .
$$

Now consider an extensive reform. By inverting (32), we get (33). Next, the nonregulated post-reform labor supply is now clearly equal to

$$
l_{N}^{\prime}=\left(p_{N}^{\prime}(1-\tau)\right)^{\frac{1}{\gamma-1}}
$$

which proves (34). Consequently their net income is $R_{N}^{\prime}=\left(p_{N}^{\prime}(1-\tau)\right)^{\frac{\gamma}{\gamma-1}}$ and their utility is

$$
u_{N}^{\prime}=\left(p_{N}^{\prime}(1-\tau)\right)^{\frac{\gamma}{\gamma-1}} \frac{\gamma-1}{\gamma} .
$$

Clearly, for these agents not to lose, it must be that

$$
1-\tau \geq \frac{p_{N}}{p_{N}^{\prime}}
$$

which coincides with (36), thus proving claim B. 
Let $T$ be the transfer to the deregulated groups and $\bar{l}^{\prime}$ the new employment level of the nonderegulated groups. Equilibrium in the nonregulated sectors reads

$l_{N}^{\prime}=(1-r) c\left(\left(p_{N}^{\prime}(1-\tau)\right)^{\frac{\gamma}{\gamma-1}}, 1, p_{N}^{\prime}\right)+\Delta r . c\left(\left(p_{N}^{\prime}(1-\tau)\right)^{\frac{\gamma}{\gamma-1}}+T, 1, p_{N}^{\prime}\right)+r^{\prime} c\left(p_{R} \bar{l}^{\prime}(1-\tau), 1, p_{N}^{\prime}\right)$.

The government's budget constraint is

$$
T \Delta r=\tau\left(r^{\prime} p_{R} \bar{l}^{\prime}+\left(1-r^{\prime}\right) p_{N}^{\prime \frac{\gamma}{\gamma-1}}(1-\tau)^{\frac{1}{\gamma-1}}\right)
$$

Substituting (87), (83) and (3) into (86) allows to compute the equilibrium value of $\bar{l}^{\prime}$, which yields

$$
\bar{l}^{\prime}=p_{N}^{\frac{1}{\gamma-1}+\frac{1}{1-\alpha}} p_{R}^{-\frac{1}{1-\alpha}}(1-\tau)^{\frac{1}{\gamma-1}} .
$$

which yields (35), thus completing the proof of claim A. We can substitute'35) into (87) and get the equilibrium value of $T$ :

$$
T=\frac{\tau(1-\tau)^{\frac{1}{\gamma-1}} p_{N}^{\frac{1}{\gamma-1}+\frac{1}{1-\alpha}}}{\Delta r} .
$$

The income of the nonderegulated group is $p_{R} \bar{l}^{\prime}(1-\tau)$, allowing us to compute its utility:

$$
u_{R}^{\prime}=u_{N}^{\prime} J^{\prime}
$$

where

$$
J^{\prime}=\frac{\gamma\left(p_{R} / p_{N}^{\prime}\right)^{-\frac{\alpha}{1-\alpha}}-\left(p_{R} / p_{N}^{\prime}\right)^{-\frac{\gamma}{1-\alpha}}}{\gamma-1} .
$$

It follows from the above analysis and (82) and (89) that for the nonderegulated to support the reform, the proportional tax rate must satisfy

$$
1-\tau \geq \frac{p_{N}}{p_{N}^{\prime}}\left(\frac{J}{J^{\prime}}\right)^{\frac{\gamma-1}{\gamma}}
$$

which proves claim C.

Finally, the deregulated group's utility is simply equal to $T+u_{N}^{\prime}$, implying from (88), (84) and (81) that for the reform to make the deregulated weakly better-off, the following must hold: 


$$
\tau(1-\tau)^{\frac{1}{\gamma-1}} p_{N}^{\frac{1}{\gamma-1}+\frac{1}{1-\alpha}} \geq \Delta r \frac{\gamma-1}{\gamma} p_{N}^{\frac{\gamma}{\gamma-1}}\left[J-\left(\frac{p_{N}^{\prime}(1-\tau)}{p_{N}}\right)^{\frac{\gamma}{\gamma-1}}\right] .
$$

This establishes claim D and completes the proof.

\subsection{Proof of Proposition 8}

Note that $\lim _{p_{R} \rightarrow 1} p_{N}=\lim _{p_{R} \rightarrow 1} p_{N}^{\prime}=1$, implying $\lim _{p_{R} \rightarrow 1} J=\lim _{p_{R} \rightarrow 1} J^{\prime}=$ 1. Denote $\tilde{\tau}=1-\frac{p_{N}}{p_{N}^{\prime}}\left(\frac{J}{J^{\prime}}\right)^{\frac{\gamma-1}{\gamma}}$. Clearly, $\lim _{p_{R} \rightarrow 1} \tilde{\tau}=0$. Observe from (88) and (84) that the deregulate group's utility, $u_{D}^{\prime}=u_{N}^{\prime}+T$ is hump-shaped in $\tau$ and reached its maximum at

$$
\tau_{\max }=\frac{(\gamma-1)\left(p_{N}^{\frac{\alpha}{1-\alpha}}-\Delta r\right)}{\gamma p_{N}^{\prime \frac{\alpha}{1-\alpha}}-(\gamma-1) \Delta r} .
$$

Clearly, $\lim _{p_{R} \rightarrow 1} \tau_{\max }=\frac{(\gamma-1)(1-\Delta r)}{\gamma-(\gamma-1) \Delta r}>0$. Consequently, for $p_{R}$ close enough to $1, \tau_{\max }>\tilde{\tau}$, implying that $u_{D}^{\prime}$ is monotonically increasing with $\tau$ over $\left[0, \tau_{\max }\right]$.

To prove Proposition 4, we show that for $p_{R}$ small enough, (90) is violated at $\tau=\tilde{\tau}$, meaning the deregulated groups are made worse-off by the reform. Since $p_{R}$ can be chosen such that $\tau_{\max }>\tilde{\tau}$, it follows that the deregulated are also worse-off for any $\tau<\tilde{\tau}$, while by definition the nonderegulated are worse-off for $\tau>\tilde{\tau}$. Clearly, then, no value of $\tau$ can implement the reform in a Pareto-improving way.

Next, substituting the value of $\tilde{\tau}$ into condition (90), and rearranging, we get the following

$$
p_{N}^{\prime \frac{1}{1-\alpha}} p_{N}^{-1} J^{\prime \frac{\gamma-1}{\gamma}}-J^{\frac{\gamma-1}{\gamma}} p_{N}^{\frac{\alpha}{1-\alpha}} \geq \frac{\gamma-1}{\gamma} \Delta r . J^{\frac{\gamma-1}{\gamma}}\left(J^{\prime}-1\right) .
$$

This equation holds with equality at $p_{R}=1$. We compute the derivative with respect to $p_{R}$ of the difference between the LHS and the RHS of (91), denoted by $E$, at $p_{R}=1$ and show it is negative. For this, note that

$$
\frac{d p_{N}}{d p_{R}}=-\frac{r}{1-r}\left(\frac{p_{R}}{p_{N}}\right)^{-\frac{1}{1-\alpha}}=-\frac{r}{1-r} \text { at } p_{R}=1
$$


implying similarly that $d p_{N}^{\prime} / d p_{R}=-r^{\prime} /\left(1-r^{\prime}\right)$ at $p_{R}=1$. This allows to compute $^{16}$

$$
\begin{aligned}
\frac{d J}{d p_{R}} & =\frac{\gamma}{(\gamma-1)(1-\alpha)(1-r)}\left(p_{R}^{-\frac{\gamma}{1-\alpha}-1} p_{N}^{\frac{\gamma+\alpha}{1-\alpha}}-\alpha p_{R}^{-\frac{1}{1-\alpha}} p_{N}^{\frac{2 \alpha}{1-\alpha}}\right) \\
& =\frac{\gamma}{(\gamma-1)(1-r)} \text { at } p_{R}=1 .
\end{aligned}
$$

Similarly $\frac{d J^{\prime}}{d p_{R}}=\frac{\gamma}{(\gamma-1)\left(1-r^{\prime}\right)}$ at $p_{R}=1$. Next, we have that

$$
\begin{aligned}
E= & \frac{d}{d p_{N}} p_{N}^{\prime \frac{1}{1-\alpha}} p_{N}^{-1} J^{\prime \frac{\gamma-1}{\gamma}}-J^{\frac{\gamma-1}{\gamma}} p_{N}^{\prime \frac{\alpha}{1-\alpha}}-\frac{\gamma-1}{\gamma} \Delta r . J^{\frac{\gamma-1}{\gamma}}\left(J^{\prime}-1\right) \\
= & \frac{\gamma-1}{\gamma} J^{\prime-\frac{1}{\gamma}} p_{N}^{\prime \frac{1}{1-\alpha}} p_{N}^{-1} \frac{d J^{\prime}}{d p_{R}}+\frac{1}{1-\alpha} p_{N}^{-1} J^{\prime \frac{\gamma-1}{\gamma}} p_{N}^{\prime \frac{\alpha}{1-\alpha}} \frac{d p_{N}^{\prime}}{d p_{R}}-p_{N}^{-2} J^{\prime \frac{\gamma-1}{\gamma}} p_{N}^{\frac{1}{1-\alpha}} \frac{d p_{N}}{d p_{R}} \\
& -\frac{\gamma-1}{\gamma} p_{N}^{\frac{\alpha}{1-\alpha}} J^{-\frac{1}{\gamma}} \frac{d J}{d p_{R}}-\frac{\alpha}{1-\alpha} J^{\frac{\gamma-1}{\gamma}} p_{N}^{\prime \frac{2 \alpha-1}{1-\alpha}} \frac{d p_{N}^{\prime}}{d p_{R}} \\
& -\left(\frac{\gamma-1}{\gamma}\right)^{2} \Delta r . J^{-\frac{1}{\gamma}}\left(J^{\prime}-1\right) \frac{d J}{d p_{R}}-\frac{\gamma-1}{\gamma} \Delta r . J^{\frac{\gamma-1}{\gamma}} \frac{d J^{\prime}}{d p_{R}} .
\end{aligned}
$$

Using the preceding expressions, we compute $E$ at $p_{R}=1$ and get

$$
\begin{aligned}
E= & \frac{1}{1-r^{\prime}}-\frac{1}{1-\alpha} \frac{r^{\prime}}{1-r^{\prime}}+\frac{r}{1-r} \\
& -\frac{1}{1-r}+\frac{\alpha}{1-\alpha} \frac{r^{\prime}}{1-r^{\prime}}-0-\frac{\Delta r}{1-r^{\prime}} \\
= & -\frac{\Delta r}{1-r^{\prime}}<0 .
\end{aligned}
$$

Therefore, by continuity, for any given $r^{\prime}>0,(91)$ is violated for $p_{R}$ greater than and close enough to 1 , which completes the proof. Note that the constraint $\tau<\tilde{\tau}$ does not apply for $r^{\prime}=0$. Proposition 2 then holds, since the analysis differs from that of Section 3 only by the choice of the numéraire.

QED.

\subsection{Example 1}

All agents consume a proportion $\rho$ of the goods, and among those, a proportion $r$ of regulated goods. $\rho$ is the same for all agents but $r$ differs among

${ }^{16} \mathrm{~A}$ useful intermediate step consists in showing that $\frac{d}{d p_{R}}\left(\frac{p_{R}}{p_{N}}\right)=\frac{1}{1-r} p_{N}^{\frac{2 \alpha-1}{1-\alpha}}$. 
agents. For any agent $i$, the goods that he consumes are randomly chosen among the total population of available goods, whose size is equal to 1 . Hence for any good, $\rho$ is also the proportion of agents who consume that good.

The distribution in the population of the proportion of regulated goods being consumed is $h(r)$, and $r$ is independent of which good the agent produces. That is, the agents who produce any good $i$ are heterogeneous and $r$ is distributed among them according to density $h()$. The maximum possible value of $r$ is $\min (\bar{r} / \rho, 1)$. If $\rho<\bar{r}$, the support of $h()$ can be any subset of $[0,1]$. For consistency we need that

$$
\int r h(r)=\bar{r}
$$

otherwise regulated goods would be under- or overrepresented in the population's preferences.

Preferences are assumed logarithmic:

$$
U_{i}=\exp \left(\frac{1}{\rho} \int_{0}^{\rho} \ln c_{i j} d j\right)-\frac{1}{\rho \gamma} l_{i}^{\gamma},
$$

where the ordering of goods here is individual specific.

We assume $\gamma=2$. . An agent who consumes a fraction $r$ of regulated goods faces a CPI equal to $p(r)=p_{R}^{r}$ and indirect utility is

$$
U\left(R_{i}, l_{i}, r\right)=\frac{R_{i}}{\rho p(r)}-\frac{1}{\rho \gamma} l_{i}^{\gamma} .
$$

. If nonregulated, his labor supply is $l_{N}(r)=p_{R}^{-r}$, his consumption of any nonregulated good is $c_{N N}(r)=\frac{R}{\rho}=p_{R}^{-r} / \rho$, his consumption of any regulated $\operatorname{good}$ is $c_{N R}(r)=\frac{R}{\rho p_{R}}=p_{R}^{-(1+r)} / \rho$. Utility is

$$
u_{N}(r)=\frac{p_{R}^{-2 r}}{2 \rho} .
$$

For regulated agents, we have $l_{N}(r)=\bar{l}, c_{R N}(r)=p_{R} \bar{l} / \rho=c_{R N}$, and $c_{R R}(r)=\bar{l} / \rho=c_{R R}$. Their utility level is

$$
u_{R}(r)=\frac{p_{R}^{1-r} \bar{l}}{\rho}-\frac{\bar{l}^{2}}{2 \rho} .
$$


To compute the equilibrium $\bar{l}$, note that the supply of any nonregulated $\operatorname{good} j$ is

$$
y_{N j}=\int_{0}^{1} h(r) l_{N}(r) d r=K
$$

where

$$
K=\int_{0}^{1} h(r) p_{R}^{-r} d r
$$

The demand for good $j$ is

$$
\begin{aligned}
c_{N j} & =\rho \bar{r} c_{R N}+\rho(1-\bar{r}) \int_{0}^{1} h(r) c_{N N}(r) d r \\
& =\bar{r} p_{R} \bar{l}+(1-\bar{r}) K .
\end{aligned}
$$

Consequently, for $c_{N j}=y_{N j}$ to hold we must have that

$$
\bar{l}=\frac{K}{p_{R}},
$$

implying that

$$
u_{R}(r)=\frac{p_{R}^{-r} K}{\rho}-\frac{K^{2} p_{R}^{-2}}{2 \rho} .
$$

Consider a reform such that $\bar{r}$ falls to $\bar{r}^{\prime}=\lambda \bar{r}$ and for any agents $r$ falls to $r^{\prime}=\lambda r$. A proportional tax $\tau$ is levied on labor income to transfer $T$ to deregulated households.

It is easy to see that the new values of labor supply and consumption for nonregulated households are

$$
\begin{aligned}
l_{N}^{\prime}(r) & =p_{R}^{-\lambda r}(1-\tau) ; \\
c_{N N}^{\prime}(r) & =p_{R}^{-\lambda r}(1-\tau)^{2} / \rho ; \\
c_{N R}^{\prime}(r) & =p_{R}^{-(1+\lambda r)}(1-\tau)^{2} / \rho .
\end{aligned}
$$

Consequently, their new utility level is

$$
u_{N}^{\prime}(r)=\frac{p_{R}^{-2 \lambda r}(1-\tau)^{2}}{2 \rho} .
$$

Confronting (93) and (95) we see that nonregulated households gain from the reform iff

$$
r \geq \frac{-\ln (1-\tau)}{(1-\lambda) \ln p_{R}}
$$


Turning now to the deregulated, their new labor supply equals that of the nonregulated but they consume more due to the transfer:

$$
\begin{aligned}
c_{D N}^{\prime}(r) & =T / \rho+p_{R}^{-\lambda r}(1-\tau)^{2} / \rho \\
c_{D R}^{\prime}(r) & =\frac{T}{\rho p_{R}}+p_{R}^{-(1+\lambda r)}(1-\tau)^{2} / \rho .
\end{aligned}
$$

Their new utility can be computed from (92):

$$
u_{D}^{\prime}(r)=u_{N}^{\prime}(r)+T p_{R}^{-\lambda r} / \rho,
$$

so that they benefit from the reform iff

$$
T p_{R}^{-\lambda r}+\frac{p_{R}^{-2 \lambda r}(1-\tau)^{2}}{2} \geq p_{R}^{-r} K-K^{2} p_{R}^{-2} .
$$

This is more likely to hold, the lower $\lambda$, the greater $T$, and the smaller $\tau$. But the effect of $r$ is ambiguous.

Finally, the nonderegulated's income is $p_{R} \bar{l}^{\prime}(1-\tau)$, implying the following consumption levels:

$$
\begin{aligned}
c_{R N}^{\prime} & =p_{R} \bar{l}^{\prime}(1-\tau) / \rho \\
c_{R R}^{\prime} & =\bar{l}^{\prime}(1-\tau) / \rho .
\end{aligned}
$$

Their utility is

$$
u_{R}^{\prime}(r)=\frac{p_{R}^{1-\lambda r} \bar{l}^{\prime}(1-\tau)}{\rho}-\frac{\bar{l}^{2}}{2 \rho} .
$$

To compute $\bar{l}^{\prime}$, we proceed as before. The supply of any nonregulated good is given by

$$
y_{N j}=\int_{0}^{1} h(r) l_{N}^{\prime}(r) d r=(1-\tau) K^{\prime}
$$

where

$$
K^{\prime}=\int_{0}^{1} h(r) p_{R}^{-\lambda r} d r .
$$

The demand for that good is 


$$
\begin{aligned}
c_{N j} & =\rho \lambda \bar{r} c_{R N}^{\prime}+\rho \bar{r}(1-\lambda) \int_{0}^{1} h(r) c_{D N}^{\prime}(r) d r+\rho(1-\bar{r}) \int_{0}^{1} h(r) c_{N N}^{\prime}(r) d r . \\
& =\lambda \bar{r} p_{R} \bar{l}^{\prime}(1-\tau)+\bar{r}(1-\lambda)\left(T+(1-\tau)^{2} K^{\prime}\right)+(1-\bar{r})(1-\tau)^{2} K^{\prime} .(99)
\end{aligned}
$$

The government's budget constraint is

$$
\begin{aligned}
(1-\lambda) \bar{r} T & =\tau(1-\lambda \bar{r}) \int_{0}^{1} h(r) l_{N}^{\prime}(r) d r+\tau \lambda \bar{r} p_{R} \bar{l}^{\prime} \\
& =\tau(1-\lambda \bar{r})(1-\tau) K^{\prime}+\tau \lambda \bar{r} p_{R} \bar{l}^{\prime} .
\end{aligned}
$$

Eliminating $T$ between (100) and (99) yields

$$
c_{N j}=\lambda \bar{r} p_{R} \bar{l}^{\prime}+(1-\lambda \bar{r})(1-\tau) K^{\prime} .
$$

Equilibrium in the market for the nonregulated good implies, from (98) and (101), that

$$
\bar{l}^{\prime}=\frac{K^{\prime}(1-\tau)}{p_{R}},
$$

from which we also get, substituting into (100):

$$
T=\frac{\tau(1-\tau) K^{\prime}}{(1-\lambda) \bar{r}}
$$

Substituting (102) into (97) and confronting with (94) we find that a household in the nonderegulated group benefits from the reform iff

$$
(1-\tau)^{2}\left[K^{\prime} p_{R}^{-\lambda r}-\frac{1}{2} K^{\prime 2} p_{R}^{-2}\right] \geq K p_{R}^{-r}-\frac{1}{2} K^{2} p_{R}^{-2} .
$$

Again, the effect of $r$ on this inequality is ambiguous.

The results reported in Table 2 were produced using a uniform distribution for $r, h(r)=\frac{1}{2 \sigma}$ for $r \in[\bar{r}-\sigma, \bar{r}+\sigma]$, with $\sigma$ set equal to $\bar{r}$. Parameter values were $p_{R}=1.4$ and $\bar{r}=0.3$.

\subsubsection{Example 2}

Goods a represented on a circle, with good $j=1$ being identified with good $j=0$. Agents are uniformly distributed over this circle, and they all 
consume a fraction $\rho$ of the goods. Hence, an agent located at $x$ consumes goods $[x, x+\rho \bmod 1]$. The distribution of preferences is independent of the allocation of producers to sectors. Hence the producers of good $j$, in terms of preferences, are uniformly allocated over the circle. The regulated goods are those such that $j \in[0, \bar{r}]$. We assume $1-\bar{r}>\rho>\bar{r}$.

The following Table summarizes the proportion of regulated goods being consumed, before and after reform, denoted by $r(x)$ and $r^{\prime}(x)$ respectively, as a function of the consumer's location:

\begin{tabular}{lll}
\hline \hline$x \in$ & $r(x)$ & $r^{\prime}(x)$ \\
\hline$\left[0, \bar{r}^{\prime}\right]$ & $\frac{\bar{r}-x}{\rho}$ & $\frac{\bar{r}^{\prime}-x}{\rho}$ \\
{$\left[\bar{r}^{\prime}, \bar{r}\right]$} & $\frac{\bar{r}-x}{\rho}$ & 0 \\
{$[\bar{r}, 1-\rho]$} & 0 & 0 \\
{$\left[1-\rho, \bar{r}^{\prime}+1-\rho\right]$} & $\frac{x+\rho-1}{\rho}$ & $\frac{x+\rho-1}{\rho}$ \\
{$\left[\bar{r}^{\prime}+1-\rho, \bar{r}+1-\rho\right]$} & $\frac{x+\rho-1}{\rho}$ & $\frac{\bar{r}^{\prime}}{\rho}$ \\
{$[\bar{r}+1-\rho, 1]$} & $\frac{\bar{r}}{\rho}$ & $\frac{\bar{r}^{\prime}}{\rho}$ \\
\hline \hline
\end{tabular}

Table A1 - Effect of reform on the proportion of regulated goods consumed, depending on one's position along the circle.

The equilibrium is computed as in the preceding example, the only difference is that the integrals $K$ and $K^{\prime}$ have to be recomputed using the distribution of the proportion of regulated goods consumed, as expressed in the preceding Table, instead of $h()$.

Hence

$$
\begin{aligned}
K & =\int_{0}^{1} p_{R}^{-r(x)} d x \\
& =\int_{0}^{\bar{r}} p_{R}^{-\frac{\bar{r}-x}{\rho}} d x+\int_{\bar{r}}^{1-\rho} d x+\int_{1-\rho}^{\bar{r}+1-\rho} p_{R}^{-\frac{x+\rho-1}{\rho}} d x+\int_{\bar{r}+1-\rho}^{1} p_{R}^{-\frac{\bar{r}}{\rho}} d x \\
& =1-\rho-\bar{r}+(\rho-\bar{r}) p_{R}^{-\frac{\bar{r}}{\rho}}+\frac{2 \rho}{\ln p_{R}}\left(1-p_{R}^{-\frac{\bar{r}}{\rho}}\right) .
\end{aligned}
$$

Similarly,

$$
K^{\prime}=1-\rho-\bar{r}^{\prime}+\left(\rho-\bar{r}^{\prime}\right) p_{R}^{-\frac{\bar{r}^{\prime}}{\rho}}+\frac{2 \rho}{\ln p_{R}}\left(1-p_{R}^{-\frac{\bar{r}^{\prime}}{\rho}}\right) .
$$


Given $r(x)$ and $r^{\prime}(x)$, the expressions for computing the individual's gains and losses are the same as in the preceding example, with $\lambda$ replaced by $r^{\prime}(x) / r(x)$. Again we can compute the total support for the reform among the deregulated and nonderegulated numerically by brute force. For the nonregulated groups, we can derive a closed-form expression as follows: Let $\Delta r_{c}=-\frac{\ln (1-\tau)}{\ln p_{R}}$. From (96), this is the critical value of $r(x)-r^{\prime}(x)$ above which a nonregulated agent gains. The support for reform among the deregulated groups partitioned by their position along the circle, as specified in Table A1, is summarized in Table A2:

\begin{tabular}{llll}
\hline \hline Location & $r(x)-r^{\prime}(x)$ & $r^{\prime}(x)$ & Support \\
\hline$\left[0, \bar{r}^{\prime}\right]$ & & $\bar{r}-\bar{r}^{\prime}<\rho \Delta r_{c}$ & $\bar{r}-\bar{r}^{\prime} \geq \rho \Delta r_{c}$ \\
{$\left[\bar{r}^{\prime}, \bar{r}\right]$} & $\frac{\bar{r}-\bar{r}^{\prime}}{\rho}$ & 0 & $\bar{r}^{\prime}$ \\
{$[\bar{r}, 1-\rho]$} & $\frac{\bar{r}-x}{\rho}$ & 0 & $\bar{r}-\bar{r}^{\prime}-\rho \Delta r_{c}$ \\
{$\left[1-\rho, \bar{r}^{\prime}+1-\rho\right]$} & 0 & 0 & 0 \\
{$\left[\bar{r}^{\prime}+1-\rho, \bar{r}+1-\rho\right]$} & $\frac{x+\rho-1-\bar{r}^{\prime}}{\rho}$ & 0 & 0 \\
{$[\bar{r}+1-\rho, 1]$} & $\frac{\bar{r}-\bar{r}^{\prime}}{\rho}$ & 0 & $\bar{r}-\bar{r}^{\prime}-\rho \Delta r_{c}$ \\
Total: $[0,1]$ & & 0 & $\rho-\bar{r}$ \\
\hline \hline
\end{tabular}

Table A2 - Computing support among the nonregulated groups

The parameter values for Table 2 are $\rho=0.4, p_{R}=1.4, \bar{r}=0.3$. 


\section{REFERENCES}

Alesina, Alberto and Allan Drazen (1991), "Why are stabilizations delayed", American Economic Review Vol. 81, No. 5, pp. 1170-1188

Amable, Bruno , Lilas Demmou and Donatella Gatti (2007), "Employment Performance and Institutions: New Answers to an Old Question", IZA discussion paper.

Beetsma Roel M. W. J.\& Xavier Debrun, 2004. "Reconciling Stability and Growth: Smart Pacts and Structural Reforms," IMF Staff Papers, vol. 51(3), pages 431-456, November.

Blanchard, Olivier, and Francesco Giavazzi (2003), "Macroeconomic Effects of Regulation and Deregulation in Goods and Labor Markets", Quarterly Journal of Economics, Vol. 118, No. 3 (Aug., 2003), pp. 879-907

Buti, Marco, Alessandro Turrini, Paul Van den Noord, Pietro Biroli (2008), "Reforms and re-elections in OECD countries", Economic Policy, Volume 25, Issue 61, 1 January 2010, Pages 61-116,

Campos, Nauro F., Paul De Grauwe and Yuemei Ji, (2017), "Structural Reforms, Growth and Inequality: An Overview of Theory, Measurement and Evidence", IZA DP No. 11159

Caselli Francesco and Nicola.Gennaioli, (2008). 'Economic and politics of alternative institutional reforms', Quarterly Journal of Economics, 123, $1197-250$.

Castanheira M.Galasso V.Carcillo S.Nicoletti G.Perotti E.Tsyganok L. (2006). 'How to gain political support for reforms', in Boeri T.Castanheira M.Faini R.Galasso V. (eds.), Structural Reform without Prejudices , Oxford University Press, Oxford.

Coe David T. \& Dennis J. Snower, 1997. "Policy Complementarities: The Case for Fundamental Labor Market Reform," IMF Staff Papers, vol. 44(1), pages 1-35, March.

Delpla, Jacques and Charles Wyplosz (2007), La fin des privilèges, payer pour réformer, Hachette littérature, 2007.

Dewatripont, Mathias, and Gerard Roland. (1992), "Economic reform 
and dynamic political constraints." Review of Economic Studies 59, no. 4 (1992): 703-730.

Dixit, Avinash and Victor Norman (1980a), Theory of International Trade, Cambridge University Press

(1980b), "The Gains from Free Trade," The Warwick Economics Research Paper Series (TWERPS) 173, University of Warwick, Department of Economics.

Fernandez, R. and Rodrik, D. (1991), "Resistance to reform: Status quo bias in the presence of individual-specific uncertainty". American economic review, pp.1146-1155.

Guesnerie, Roger and Kevin Roberts (1987), "Minimum wage legislation as a second best policy", European Economic Review, 31, 490-498

Grandmont, Jean-Michel and Daniel MacFadden (1972), "A technical note on classical gains from trade", Journal of International Economics, 2, $109-125$

Grüner, Hans Peter (2002), "Unemployment and Labor-market Reform: A Contract Theoretic Approach ", Scandinavian Journal of Economics, 104(4), December 2002, pp. 641-656.

Grüner, Hans Peter (2013), "The Political Economy of Structural Reform and Fiscal Consolidation Revisited", European Economy Economic Papers 487, April 2013.

Ilzetski, Ethan (2018), "Tax reform and the political economy of the tax base", Journal of Public Economics, 164, 197-210

Krueger, Anne O. (1974), "The Political Economy of the Rent-Seeking Society." American Economic Review 64: 291-303

Marceau, N. and R. Broadway (1994), "Minimum wage legislation and unemployment insurance as instruments for redistribution", Scandinavian Journal of Economics, 96, 67-81

Saint-Paul, Gilles (1993), "On the political economy of labor market flexibility", NBER Macroeconomics Annual 1993, Volume 8, pages 151-196

Saint-Paul, Gilles (1994), "Do Labor Market Rigidities Fulfill Distributive 
Objectives?: Searching for the Virtues of the European Model," IMF Staff Papers, vol. 41(4), pages 624-642, December.

Saint-Paul, Gilles (2007), "Making sense of Bolkestein-bashing: Trade liberalization under segmented labor markets", Journal of International Economics, 2007, vol. 73, issue 1, 152-174

Saint-Paul, Gilles, Davide Ticchi and Andrea Vindigni (2016), "A theory of political entrenchment", Economic Journal, Volume 126, Issue 593, 1 June 2016, Pages 1238-1263

Tullock, Gordon (1967), "The Welfare Costs of Tariffs, Monopolies, and Theft." Western Economic Journal 5 (June): 224-232.

Tullock, Gordon (2003), "The Origin Rent-Seeking Concept" International Journal of Business and Economics 2(1): 1-8. 